
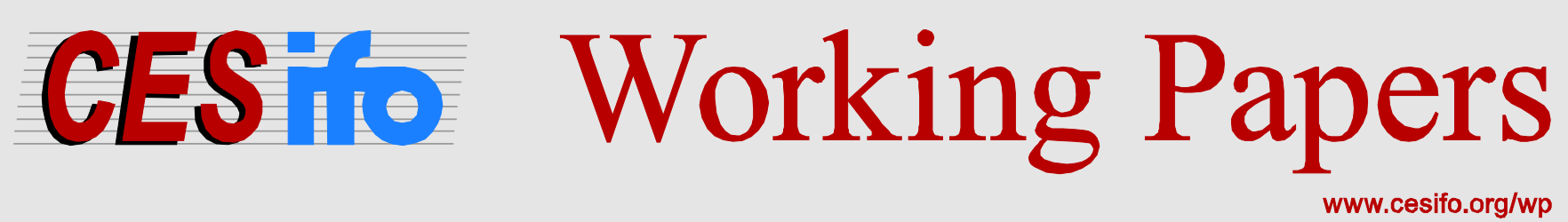

\title{
Income Redistribution in Open Economies
}

\author{
Áron Tóbiás
}

CESIFO WORKING PAPER NO. 5378

CATEgORY 1: PUBLIC FINANCE

MAY 2015

Presented at CESifo Area Conference on Global Economy, May 2015

An electronic version of the paper may be downloaded

- from the SSRN website:

- from the RePEc website:

- from the CESifo website:

wWw.SSRN.com

www.RePEc.org

www.CESifo-group.org/wp 


\title{
Income Redistribution in Open Economies
}

\begin{abstract}
I propose a model of income redistribution in an open-economy environment. The world consists of a finite number of countries whose governments seek to maximize the welfare of their low-skilled populations by taxing skilled workers' labor income. While tax competition limits the extent to which redistribution is possible-as compared to the closed-economy outcome-when skilled people are internationally mobile, I argue that race to the bottom does not necessarily occur, even if the number of countries becomes arbitrarily large. The asymptotic sustainability of the welfare state crucially depends on the statistical properties of the probability distribution of skilled people's location preferences.
\end{abstract}

JEL-Code: D820, F220, H210, H730.

Keywords: income redistribution, international migration, tax competition, race to the bottom.

\author{
Áron Tóbiás \\ Department of Economics \\ Yale University \\ New Haven / CT / USA \\ aron.tobias@yale.edu
}

May 18, 2015

I am indebted to Dirk Bergemann for the continuous support, guidance, and encouragement he provided me with throughout this research project. I am grateful to Johannes Hörner, Larry Samuelson, Alex Smolin, Aleh Tsyvinski, and Glen Weyl for the enlightening conversations I had with them about the ideas expressed in this paper. In addition, I thank Daniel Barron, YeonKoo Che, Eduardo Faingold, Tibor Heumann, Lorenzo Magnolfi, Dávid Krisztián Nagy, Zvika Neeman, Camilla Roncoroni, Gabriella Santangelo, Ennio Stacchetti, Philipp Strack, Noam Tanner, and other seminar participants at Yale University for their useful comments and suggestions. All remaining errors and omissions are mine. 


\section{Introduction}

\subsection{Motivation}

What limitations does international labor mobility impose on the extent to which income redistribution is feasible? In this paper, I seek to explore this question by examining a world economy that consists of a finite number of countries, each inhabited by low-skilled people who can neither work nor move and high-skilled people who provide labor effort that can be converted into consumption. The government's goal is to maximize low-skilled people's welfare subject to the requirement that high-skilled persons not find it profitable to imitate being low-skilled and collect welfare benefitsintended for low-skilled people-instead of working. High-skilled people are internationally mobile; they may leave the country if they find that supporting the low-skilled would impose too heavy a burden on them. They also take their personal idiosyncratic location preferences into account when making migration decisions. Labor mobility, in turn, gives rise to strategic interaction between governments by making the aggregate resource constraint endogenous to the tax policy they seek to implement, and imposes a further constraint on redistributive goals. I define and characterize an equilibrium concept according to which governments seek to provide low-skilled people with as much consumption as possible, subject to incentive compatibility and feasibility adjusted for migration concerns.

According to the resulting equilibrium concept, there exists a unique symmetric equilibrium in which all countries offer the same allocation. Consequently, the equilibrium mass of high-skilled people will be the same as in the closed economy. However, the equilibrium allocation is typically less generous than the one that would prevail in the absence of migration, in that low-skilled people's consumption is lower in the open-economy equilibrium. This is because the sheer threat of losing skilled workforce compels each country to diminish resource extraction from high-skilled people. This effect becomes stronger in the presence of more countries and, accordingly, the generosity of the equilibrium open-economy income redistribution scheme decreases in the number of countries. Essentially, each country's government is faced with a fundamental trade-off: the only way to retain and attract high-skilled people is to extract fewer resources from them at the cost of making redistribution towards the low-skilled less generous.

As the number of country grows, one might expect that governments engage in an ever fiercer tax competition for human capital and the ultimate outcome is race to the bottom-that is, mutual brain drain becomes so strong that it leads to the collapse of the welfare state and no income redistribution whatsoever is feasible asymptotically. Despite what economic intuition might first suggest, however, redistribution does not necessarily collapse as the number of countries diverges to infinity. This is because even though tax competition between countries for high-skilled workers becomes fiercer with there being more countries, those people also exhibit idiosyncratic location preferences for particular countries beyond pure economic considerations in formulating their migration decisions. If mobility frictions embodied by those preferences are sufficiently strong, then the extent to which more high-skilled people can be attracted at the expense of diminishing welfare benefits remains limited. In this case, 
governments' incentives to further decrease taxes in order to induce human-capital flight from other countries are diminished, even asymptotically as each country faces a multitude of other countries to attract skilled workers from. This dampening effect on tax competition prevents race to the bottom from occurring for a certain class of distributions of idiosyncratic location preferences. I demonstrate also that income redistribution does collapse as high-skilled people's idiosyncratic preferences disappear-that is, as labor mobility becomes perfectly frictionless-even for as few as two countries.

The main results of this paper are thus twofold. First, as far I know, the characterization of asymptotics with respect to the number of countries in models of open-economy tax competition has been a hitherto unexplored area of the theoretical public-finance literature. In this sense, the article proposes also a methodological and conceptual innovation. Second, the analysis reveals that the subtle details of the distribution of idiosyncratic location preferences are of crucial importance in evaluating the effects of international labor mobility on the sustainability of income redistribution: The statistical properties of those preferences determine whether or not international tax competition destroys the welfare state by triggering a race to the bottom.

The rest of the paper proceeds as follows. Subsection 1.2 reviews the related literature. Section 2 sets forth the formal model of the analysis. Section 3 characterizes the laissez-faire outcome that prevails without government interference, and also the benchmark redistribution scheme that would be implemented by a single government in a closed economy. In Section 4, I demonstrate the manner in which high-skilled people's migration decisions are affected by the governments' redistribution policies and describe how the world economy's high-skilled workers are distributed across countries subsequent to migration. In Section 5, I propose an equilibrium concept that captures the strategic interaction between countries' governments and show the existence, uniqueness, and key characteristics of that equilibrium. Section 6 analyzes how the equilibrium allocation depends on the number of countries. In particular, the asymptotic properties of the equilibrium are exhibited as the number of countries grows without bound. In addition, it is also here that I examine the consequences of frictionless international mobility unhampered by idiosyncratic location preferences. Section 7 illustrates several numerical examples. In Section 8, I provide a detailed discussion of the interpretation of high-skilled people's location preferences. I also propose an empirical strategy of measuring and operationalizing them, providing a bridge between the theoretical implications of the model and real-world data. Section 9 concludes, discusses the model's key assumptions, and proposes possible extensions. Technical proofs are reported in the appendices.

\subsection{Related Literature}

The complications associated with the effects of migration on income redistribution had been recognized shortly after the birth of the Mirrleesian public-finance paradigm. ${ }^{1}$ Mirrlees (1982) considers the implications of differential taxation of income earned

\footnotetext{
${ }^{1}$ Indeed, Mirrlees (1971, p. 176) notes already in his seminal work about the trade-off between efficiency and equity inherent in income redistribution that "the threat of migration is a major influence on the degree of progression in actual tax systems."
} 
abroad and that earned at home. In the work of Wilson (1980), the social planner takes emigrants' welfare into consideration but restricts attention to linear income taxation. In a subsequent article, Wilson (1982) provides a characterization of tax systems that are optimal from the point of view of a hypothetical worldwide government seeking to maximize the social welfare of the global population, and shows that the optimal worldwide tax policy exhibits aggregate production efficiency. Bhagwati and Hamada (1982) present a model that involves dynamic features in terms of human-capital accumulation. They consider only linear taxes, which are levied separately on emigrants and residents, and find that the optimal marginal tax rate is lower when the economy is open. ${ }^{2}$

More recently, Leite-Monteiro (1997) presented a two-country model with asymmetric initial population structures and showed that the country with an initially lower level of high-skilled population may actually implement a more generous redistribution scheme via attracting high-skilled people from the other country. ${ }^{3}$ Hamilton and Pestieau (2005) study the effects of migration on income redistribution under the assumption that the tax policy is determined by majority voting. Gordon and Cullen (2012) analyze how the presence of a higher-level government can mitigate the effects of tax competition between lower-level governments on income redistribution, and the implications of these findings for the division of redistribution between different levels of government. In a two-country model with finitely many skill types, Bierbrauer et al. (2013) demonstrate that neither government taxes the highest-skilled people in any equilibrium and the lowest-skilled cannot ever receive any transfers, either, if people are perfectly mobile.

In terms of capital taxes, Mendoza and Tesar (2005) provide an explanation for why increased integration of financial markets within the European Union has failed to give rise to race to the bottom. Since consumption taxes had become harmonized within the $\mathrm{EU}$, the only way to recover tax revenues lost due to decreased capital tax rates and maintain fiscal solvency would be to increase taxes on labor. However, this leads to considerable distortions provided that labor supply is sufficiently elastic, which deters governments from engaging in tax competition in terms of levies on capital. Itskhoki (2008) emphasizes yet another aspect of how the openness of an economy may influence tax policies, showing that the international integration of goods markets may exacerbate the classical trade-off between equity and efficiency in the design of redistributive tax systems. It is possible that welfare gains from international trade can be realized only at the cost of equity, because greater inequality caused by trade liberalization may be accompanied with an intensified trade-off between equity and efficiency. In this case, the social planner may need to optimally curb the progressivity of income taxation and endure greater inequality in response to openness to trade. This finding may undermine the conventional wisdom that the distributional effects of openness to

\footnotetext{
${ }^{2}$ For other early Mirrleesian models of optimal taxation in open-economy environments, see the monograph edited by Bhagwati and Wilson (1989).

${ }^{3}$ See also Piaser (2007), who considers two ex-ante symmetric countries with Rawlsian socialwelfare functions. Lipatov and Weichenrieder (2012) extend this analysis to asymmetric countries and government objectives other than the Rawlsian one.
} 
international trade can be mitigated by more progressive income taxation. ${ }^{4}$

As for empirical evidence on the interaction between tax policies and international migration, Kleven et al. (2013) show that taxes on foreigners' income in the destination countries strongly influence professional soccer players' migration across borders, which suggests that international labor mobility imposes a substantial check on top income-tax rates. That high-skilled foreigners respond to tax instruments has been highlighted also by Kleven et al. (2014), who argue that Denmark has been successful in attracting high-income immigrants by offering tax incentives. ${ }^{5}$

Simula and Trannoy (2010) consider two countries, one of which is "large," nonstrategic, and exogenously implements a given linear tax schedule. The other country is "small" and is populated by a continuum of taxpayers with skill-dependent migration costs. The small country's Rawlsian government seeks to ensure that no migration occurs in equilibrium by imposing skill-dependent participation constraints. Their main finding is that the sheer threat of migration may well render the optimal tax schedule not only regressive but "perverse," in the sense that the optimal (marginal) tax rate may be negative for the highest-skilled people. Intuitively, if high-skilled workers are the ones who are the most willing to emigrate, it is less mobile middle-skilled persons who must bear the costs of subsidizing the poor under the optimal redistributive tax policy.

By making the threat that the presence of a foreign economy embodies endogenous, the "curse of the middle-skilled" disappears. This is demonstrated by Morelli et al. (2012), who consider a three-type model with two utilitarian (as opposed to Rawlsian) tax jurisdictions, both being strategic. Unlike in Simula and Trannoy (2010), governments' endeavor to preclude migration at all costs is replaced by the endogeneity of the budget constraint: that is, governments take account of how potential migration affects the aggregate availability of resources. The conclusion that migration threats decrease social welfare still prevails, though, even if no actual migration takes place in equilibrium.

The classical tax formulae for closed-economy Mirrleesian models with a continuum of skill types (Diamond, 1998; Saez, 2001) are recomputed and reinterpreted by Lehmann et al. (2014) for open economies in a model with two symmetric countries and Rawlsian governments. Based on these formulae, they show that the shape of the income-tax function crucially depends on the shape of the semi-elasticity of migration

\footnotetext{
${ }^{4}$ From a more general point of view, Caplin and Nalebuff (1997, p. 333) highlight the importance of and provide a general theoretical underpinning for the interaction between institutional frameworks and competition between institutions; as they put it, "the policy that each institution adopts depends on the memberships, and the memberships depend upon the policies of all institutions." In the current framework, this message can be interpreted as incomeredistribution policies depending on high-skilled people's migration decisions and, vice versa, induced migration depending on redistribution policies.

${ }^{5}$ For empirical analyses of bilateral migration flows in the modern era, see Abel and Sander (2014) and Castles et al. (2013). The manuscript by Goldin et al. (2011) provides a historical overview of the trends and determinants of international migration, as well as a discussion of future challenges. Gordon and Hines (2002) provide a review of international taxation in general. Hines (2006) and Hines and Summers (2009) discuss the challenges governments are faced with in designing optimal tax policies in a globalized economy.
} 
(as a function of skill), defined as the percentage change in the mass of taxpayers of a given skill induced by a unit change in their consumption. The present paper reinforces the crucial role played by the sensitivity of the mass of taxpayers with respect to their welfare options in a setting with more than two countries, including asymptotic results, albeit in a simplified framework (with there being two skill types as opposed to a continuum of them).

\section{Model}

\subsection{Setup}

The world consists of $n \in \mathbb{N}$ symmetric countries. Each country $i \in N$ (letting $N$ denote the set of the first $n$ positive integers) is populated by a continuum of people of unit mass. Production technology is linear in labor effort; each unit of effort utilized in production yields $z>0$ units of a representative good that can be consumed.

People in each country $i \in N$ can be either high-skilled or low-skilled. Low-skilled people can neither supply labor effort nor migrate between countries, and they value only consumption. The fraction of low-skilled people is given by $1-\alpha$, where $\alpha \in$ $(0,1)$; the rest of the population are high-skilled. Skill type is private information and is not directly observable.

\subsection{Location Preferences}

High-skilled people are heterogeneous with respect to their location preferences. For a high-skilled person initially living in country $i$, location preferences are represented by real numbers $\left(\psi_{i j}\right)_{j \in N} \in \mathbb{R}^{n}$ in a such a way that the greater the value of $\psi_{i j}$, the less the person prefers living in country $j \in N$. High-skilled people's location-preference parameters are distributed independently and identically across destinations (including the home country) according to the probability density function $h: \mathbb{R} \rightarrow \mathbb{R}_{+}$. Hence, in any country $i \in N$, the location-preference profile $\left(\psi_{i j}\right)_{j \in N} \in \mathbb{R}^{n}$ has a density of $\prod_{j \in N} h\left(\psi_{i j}\right)$ across high-skilled people.

Assumption 1 The distribution of location preferences satisfies the following conditions:

(i) $h$ is strictly positive on the whole real line and continuously differentiable;

(ii) $h$ is log-concave - that is, the composite function $\log \circ h$ is concave.

Many ubiquitous probability density functions satisfy this assumption, including the Gaussian, logistic, and extreme-value distributions. In what follows, let $H(\psi) \equiv$ $\int_{-\infty}^{\psi} h(s) \mathrm{d} s$ denote the value of the cumulative distribution function $H: \mathbb{R} \rightarrow[0,1]$ associated with $h$.

The difference $\psi_{i j}-\psi_{i i}$, representing the relative preference of staying in country $i$ as compared to moving to another country $j$, can be thought of as encompassing pecuniary, psychological, and administrative costs of migration. This difference can also be negative, which is to be interpreted as a person exhibiting an idiosyncratic preference for living in a country different from her homeland. I will return to the discussion of the structure of location preferences in Section 8. 


\subsection{Utilities}

If a high-skilled person with location-preference profile $\left(\psi_{i j}\right)_{j \in N} \in \mathbb{R}^{n}$, originally residing in country $i \in N$, consumes $d \geq 0$ units, supplies $e \geq 0$ units of labor effort, and decides to move to country $j \in N$ (or decides to stay in country $i$ in case $j=i$ ), then her utility is given by $u(d)-v(e)-\psi_{i j}$.

Assumption 2 The functions $u: \mathbb{R}_{+} \rightarrow \mathbb{R}$ and $v: \mathbb{R}_{+} \rightarrow \mathbb{R}$ satisfy the following:

(i) $u$ and $v$ are twice continuously differentiable;

(ii) $u^{\prime}>0, u^{\prime \prime}<0$;

(iii) $v^{\prime} \geq 0, v^{\prime \prime}>0$, and $v(0)=0{ }^{6}$

(iv) $z u^{\prime}(0)>v^{\prime}(0)$;

(v) $\lim _{c \rightarrow \infty} u(c)=\infty$;

(vi) $\lim _{e \rightarrow \infty}\{u(z e)-v(e)\}=-\infty$.

\section{Closed-Economy Benchmark}

The purpose of this section is to describe and characterize two specific allocations that arise when the economy is closed. Firstly, if there are no governments, then high-skilled people supply their effort in a competitive, frictionless labor market. Since low-skilled people cannot work, they do not consume anything. I call the resulting outcome the laissez-faire allocation. Secondly, I present a characterization of the income redistribution scheme, termed the closed-economy benchmark allocation, that arises when the government of a single closed economy seeks to maximize low-skilled people's welfare subject to incentive compatibility and the aggregate resource constraint. These allocations represent two extremes: the laissez-faire allocation involves no redistribution at all, while the closed-economy benchmark allocation exhibits the most generous redistribution scheme that can possibly be achieved in the closed economy. Keeping these two extreme points of reference in mind will prove useful in assessing the extent to which international labor mobility curtails governments' ability to redistribute income.

\subsection{Laissez-Faire Allocation}

Suppose for a moment that there are no governments. In this case, the economy presented in Subsection 2.1 can be thought of as consisting of a representative firm that uses linear technology to convert labor effort into consumption. In a competitive environment, this firm would be paying its high-skilled employees a wage of $z$. Hence, if a high-skilled person supplied $e \geq 0$ units of labor effort, then her gross income

\footnotetext{
${ }^{6}$ In spite of the fact that the first derivative of $v$ is assumed to be merely non-negative, it is nevertheless not difficult to see that the condition $v^{\prime \prime}>0$ ensures that $v$ is strictly increasing. In particular, $v^{\prime}(e)$ can vanish only if $e=0$.
} 
would be given as ze. Then, the labor supply of high-skilled people is determined by the solution to the following optimization problem:

$$
\sup _{e \geq 0}\{u(z e)-v(e)\} .
$$

Since $z u^{\prime}(0)-v^{\prime}(0)>0$ and $\lim _{e \rightarrow \infty}\{u(z e)-v(e)\}=-\infty$ by Assumption 2 and the objective function is strictly concave, there exists a unique $\bar{e}>0$ solving this problem. Low-skilled people, on the other hand, cannot work and hence consume nothing in a competitive economy without the presence of a government redistributing labor income.

Definition 1 The allocation $(0, z \bar{e}, \bar{e})$-where 0 denotes low-skilled people's consumption, $z \bar{e}$ high-skilled people's consumption, and $\bar{e}$ high-skilled people's labor supply as determined by the unique solution to (1) - is said to be the laissez-faire allocation.

\subsection{Redistribution in a Closed Economy}

Now suppose that there is only one country (or, alternatively, many countries with closed borders between which migration is not possible) controlled by a benevolent government that seeks to redistribute income from high-skilled people to low-skilled ones. Specifically, assume that the government's social-welfare objective is Rawlsian in the sense that it values only low-skilled people's consumption.

This stylized Rawlsian social-welfare objective, on the one hand, corresponds to a society that consists of two types of people: a "core population" (say, retirees) whose welfare depends solely on how large benefits they can derive from income redistribution, and a "working population" that provides the resources necessary to support the core population. This approximation to the government's objective is plausible if the core population actively participates in the democratic political process in order to elect officials that implement Rawlsian welfare policies. ${ }^{7}$ Crudely put, the government uses high-skilled people as a mere resource in order to support low-skilled people. On the other hand, the Rawlsian social-welfare criterion gives rise to the most egalitarian net-income profile that can possibly be achieved and is thus likely to exaggerate real-world governments' redistributive endeavors. Therefore, it is a useful benchmark in considering the extent to which international labor mobility curtails governments' ability to strive against economic inequality (Lehmann et al., 2014).

Suppose that the government wishes to implement a given allocation $(c, d, e) \in$ $\mathbb{R}_{+}^{3}$-where $c$ denotes low-skilled people's consumption, $d$ high-skilled people's consumption, and $e$ high-skilled people's labor supply-by means of a direct, centralized, command-and-control mechanism. ${ }^{8}$ Given the Rawlsian social-welfare objective and the assumption that low-skilled people cannot work at all, the government seeks to

\footnotetext{
${ }^{7}$ See, for instance, Campbell (2003), Kotlikoff and Burns (2005), and Lynch (2006).

${ }^{8}$ That is, I assume that the government has all the resources in the economy, including highskilled people's potential effort, at its disposition and it has the power to arrange them as it pleases. Admittedly unrealistic as it is, this assumption is not unusual in the modern literature on optimal income taxation-see also Golosov et al. (2007) for a review of alternative ways of implementation.
} 
maximize low-skilled people's consumption subject to two constraints. First, it has to make sure that high-skilled people have no incentive to pretend to be low-skilled (incentive compatibility). ${ }^{9}$ Second, it has to maintain budget balance: total consumption of both low-skilled and high-skilled people in the economy must not exceed what is produced using high-skilled people's labor effort. From a slightly different point of view, the implicit tax collected from high-skilled people (defined as the difference between their gross labor income and their consumption) must cover the costs of providing low-skilled people with consumption. Formally, the government seeks to solve the following problem:

$$
\begin{aligned}
\sup _{(c, d, e) \in \mathbb{R}_{+}^{3}} c \quad \text { such that } \\
u(d)-v(e) \geq u(c), \\
(1-\alpha) c \leq \alpha(z e-d) .
\end{aligned}
$$

Definition 2 An allocation $(c, d, e) \in \mathbb{R}_{+}^{3}$ is said to be a closed-economy benchmark allocation if it solves the problem (2).

Proposition 1 There exists a unique closed-economy benchmark allocation $\left(c_{1}, d_{1}, e_{1}\right) \in \mathbb{R}_{+}^{3}$. This allocation satisfies $c_{1}>0, d_{1}>0, e_{1}>0$, and the following conditions:

$$
\begin{aligned}
\frac{v^{\prime}\left(e_{1}\right)}{u^{\prime}\left(d_{1}\right)} & =z, \\
u\left(d_{1}\right)-v\left(e_{1}\right) & =u\left(c_{1}\right), \\
(1-\alpha) c_{1} & =\alpha\left(z e_{1}-d_{1}\right) .
\end{aligned}
$$

Proof See Appendix A.

The closed-economy benchmark allocation $\left(c_{1}, d_{1}, e_{1}\right)$ is the best a benevolent Rawlsian government can implement in a closed economy. According to this allocation, the "information rents" obtained by high-skilled people-stemming from the fact that skill type is unobservable to the government ex ante-are driven down to the point where they are indifferent between working and pretending to be low-skilled. However, their labor-effort supply is undistorted at the margin; (3) shows that the ratio of the marginal disutility of effort to the marginal utility of consumption equals to "shadow wage" $z$, which would be the equilibrium market wage in a laissez-faire economy. This property of the closed-economy benchmark allocation can be conceived of as a version of the well-established no-distortion-at-the-top principle.

\footnotetext{
${ }^{9}$ As long as high-skilled people are required to supply positive labor effort, low-skilled people are unable to imitate them given that they cannot work. Hence, no incentive-compatibility constraint need be imposed for low-skilled people. I assume also that once the government announces an allocation, it must commit to it. This ensures that once a high-skilled person is observed to work, and thus has her skill type revealed, the government is forbidden from exploiting this information ex post.
} 


\section{Migration}

International labor mobility ultimately makes the mass of high-skilled people residing in each country endogenous to the consumption-effort allocations chosen by governments. Consequently, it is crucial for governments to appreciate how allocations offered by them-together with idiosyncratic location preferences and taking other countries' offers as given-determine high-skilled people's location choices when the borders are open.

From now on, it is assumed that high-skilled people can move freely across countries. Each country's government offers high-skilled people a consumption-effort allocation and low-skilled people a consumption allocation (since the latter are unable to work). I impose the assumption that countries' governments are forbidden from discriminating against people on the basis of national origin. That is, if two people report to have the same skill level, then they must be offered the same allocation. I assume also that countries do not screen for location preferences. The assumptions that allocations cannot depend on which countries people come from and that there are no exogenous or endogenous administrative restrictions on migration can be justified by envisaging the countries as being members of a supranational institution such that governments are legally bound to ensure the free movement of persons and forbidden from discriminating between taxpayers on the basis of national origin.

\subsection{Location Choices}

High-skilled people's location choices depend on their location preferences and the consumption-effort allocations available in each country. Specifically, suppose that countries offer such consumption-effort allocations that the utility level attained by a high-skilled person in country $i \in N$ is $x_{i} \in \mathbb{R}$. Fix any pair of countries $i, j \in N$ (with possibly $i=j)$. A high-skilled person of location-preference profile $\left(\psi_{j k}\right)_{k \in N} \in \mathbb{R}^{n}$ originally from country $j$ will migrate into (or stay in) country $i$ if and only if ${ }^{10}$

$$
x_{i}-\psi_{j i} \geq x_{k}-\psi_{j k} \quad \text { for all } k \in N \backslash\{i\},
$$

or

$$
\psi_{j k} \geq \psi_{j i}-\left(x_{i}-x_{k}\right) \quad \text { for all } k \in N \backslash\{i\} .
$$

Therefore, the mass of high-skilled people from country $j$ that will choose to reside in country $i$ is given as follows:

$$
\begin{aligned}
& \int_{\psi_{j i} \in \mathbb{R}} h\left(\psi_{j i}\right)\left(\prod_{k \in N \backslash\{i\}} \int_{\psi_{j k} \geq \psi_{j i}-\left(x_{i}-x_{k}\right)} h\left(\psi_{j k}\right) \mathrm{d} \psi_{j k}\right) \mathrm{d} \psi_{j i} \\
= & \int_{-\infty}^{\infty} h\left(\psi_{j i}\right) \prod_{k \in N \backslash\{i\}}\left[1-H\left(\psi_{j i}-\left(x_{i}-x_{k}\right)\right)\right] \mathrm{d} \psi_{j i} .
\end{aligned}
$$

\footnotetext{
${ }^{10}$ Issues associated with indifference can be safely assumed away, given that the distribution of location preferences is atomless.
} 
Summing over all countries $j \in N$, it follows that the mass of those high-skilled people in the world economy that ultimately choose to reside in country $i$ when countries offer high-skilled people utility levels $\left(x_{j}\right)_{j \in N}$ is given as follows:

$$
\sum_{j \in N} \int_{-\infty}^{\infty} h\left(\psi_{j i}\right) \prod_{k \in N \backslash\{i\}}\left[1-H\left(\psi_{j i}-\left(x_{i}-x_{k}\right)\right)\right] \mathrm{d} \psi_{j i} .
$$

\subsection{Symmetric Outside Options}

Suppose now that country $i$ offers such a consumption-effort menu that the utility of high-skilled people residing in country $i$ is $x \in \mathbb{R}$, whereas all other countries offer the same utility level $y \in \mathbb{R}$. In this case, the quantity in (7), which I denote as $M(x \mid y)$, is given as follows:

$$
M(x \mid y) \equiv n \int_{-\infty}^{\infty} h(\psi)[1-H(\psi-(x-y))]^{n-1} \mathrm{~d} \psi
$$

That is, $M(x \mid y)$ gives the mass of high-skilled people that wind up residing in a particular country if that country offers high-skilled people a utility level of $x$ while they can obtain a utility level of $y$ in any other country. ${ }^{11}$

For a given $y \in \mathbb{R}$, let

$$
m(x \mid y) \equiv \frac{\partial M(x \mid y)}{\partial x}
$$

denote the partial derivative of the function $x \mapsto M(x \mid y)$. Intuitively, this quantity provides the marginal sensitivity of a given country's skilled population when that country marginally adjusts the utility level obtained by high-skilled people.

The next three lemmata-whose proofs are reported in Appendix B-summarize several key technical properties of the function defining the mass of high-skilled people and this quantity's marginal sensitivity to the utility level obtained by high-skilled people. In particular, Lemma 1 shows that the partial derivative $m(x \mid y)$ is always welldefined and can be computed in the expected way (that is, by differentiating under the integral sign). These lemmata will be used later to characterize migration flows in equilibrium.

Lemma 1 For any $y \in \mathbb{R}$, the function $x \mapsto M(x \mid y)$ is strictly increasing, differentiable, and its derivative is given as follows:

$$
m(x \mid y) \equiv \frac{\partial M(x \mid y)}{\partial x}=n(n-1) \int_{-\infty}^{\infty} h(\psi) h(\psi-(x-y))[1-H(\psi-(x-y))]^{n-2} \mathrm{~d} \psi ;
$$

that is, differentiation under the integral sign is valid.

Lemma 2 The function $(x, y) \mapsto M(x \mid y)$ is jointly continuous.

Lemma 3 For any $y \in \mathbb{R}$, the function $x \mapsto M(x \mid y)$ is log-concave. ${ }^{11}$ The index of the integration variable $\psi$ in (6) and (7) is reported only in order to highlight the
intuitive interpretation. Suppressing it makes no difference mathematically. 
If country $i$ offers high-skilled people a utility level of $x \in \mathbb{R}$ and all other countries offer them a utility level of $y \in \mathbb{R}$, then the same mass of high-skilled people will arrive from each country by the assumption of the symmetry of the distribution of location preferences-see (6). Therefore, $M(x \mid y)$ can be decomposed as follows:

$$
\begin{aligned}
M(x \mid y) & =\underbrace{\int_{-\infty}^{\infty} h(\psi)[1-H(\psi-(x-y))]^{n-1} \mathrm{~d} \psi}_{\text {mass of stayers }} \\
& +\underbrace{(n-1) \int_{-\infty}^{\infty} h(\psi)[1-H(\psi-(x-y))]^{n-1} \mathrm{~d} \psi .}_{\text {mass of immigrants }}
\end{aligned}
$$

The first term corresponds to the mass of high-skilled people who had originally resided in country $i$ and decided to stay there. The second term measures the flows of immigrants from the rest of the world, the other $n-1$ countries. Correspondingly, the derivative of $M(x \mid y)$ with respect to the utility level $x$ offered by country $i$ can be decomposed into two effects:

$$
\begin{aligned}
m(x \mid y) & =\frac{1}{n} m(x \mid y)+\frac{n-1}{n} m(x \mid y) \\
= & \underbrace{(n-1) \int_{-\infty}^{\infty} h(\psi) h(\psi-(x-y))[1-H(\psi-(x-y))]^{n-2} \mathrm{~d} \psi}_{\text {retention effect }} \\
+ & \underbrace{(n-1)^{2} \int_{-\infty}^{\infty} h(\psi) h(\psi-(x-y))[1-H(\psi-(x-y))]^{n-2} \mathrm{~d} \psi}_{\text {attraction effect }} .
\end{aligned}
$$

The retention effect, on the one hand, measures how sensitive the mass of stayers is to the utility option offered by country $i$. The attraction effect, on the other hand, expresses the marginal flow of high-skilled immigrants arriving from the rest of the world induced by improved welfare options attainable by high-skilled workers in country $i$.

\section{Equilibrium}

The goal of this section is to define a notion of equilibrium corresponding to individual countries' seeking to maximize the welfare of their low-skilled population in an openeconomy environment, taking the endogeneity of the mass of high-skilled people into account. After showing that there exists a unique symmetric equilibrium according to this concept, I give a detailed characterization of that equilibrium.

\subsection{Equilibrium Concept, Existence, and Uniqueness}

If borders are open and high-skilled workers are free to migrate into any country of their choice, then each government faces a trade-off. In keeping seeking to redistribute as much income towards the core population as it can, it must take account of the threat that if such redistributive goals impose too heavy a burden on high-skilled people, 
then those people can simply leave for another country. In what follows, I define and analyze an equilibrium concept corresponding to this situation.

I maintain the assumption that governments are Rawlsian-that is, they seek to maximize the consumption of low-skilled people who can neither work nor leave the country. In an open economy, in general, the endogeneity of the population to the policy implemented by the government gives rise to difficult normative and philosophical questions as to which people's welfare ought to be counted in the social welfare objective and which of those objectives can be deemed reasonable and/or equitable (see Blackorby et al., 2005; Mansoorian and Myers, 1997; Mirrlees, 1982). In the current context, at any rate, maintaining the assumption introduced in Subsection 3.2 that each government cares only about the welfare of the "core population" of low-skilled people does not lead to ambiguities in terms of the identity and the size of that populace, given that low-skilled people are immobile. In other words, the Rawlsian objective continues to capture each government's seeking to maximize the welfare of "its own poor" without having to redefine what "own" and "poor" mean upon opening up the economy. ${ }^{12}$

When the borders are open, incentive compatibility is no longer the only restriction that keeps governments from fully expropriating high-skilled people's labor effort. Indeed, if high-skilled people are unhappy with the consumption-effort allocation they are offered in a given country, they may leave for another country. In other words, the dependence of the size of the high-skilled population on the allocation they are offered makes the budget constraint endogenous. Specifically, if the utility level that high-skilled people can attain in any other country is given by $y \in \mathbb{R}$ and country $i \in N$ offers low-skilled people $c \geq 0$ units of consumption and high-skilled people $d \geq 0$ units of consumption and requires $e \geq 0$ units of labor effort from them, then feasibility of the allocation requires that the following constraint hold:

$$
(1-\alpha) c+\alpha M(u(d)-v(e) \mid y) d \leq \alpha M(u(d)-v(e) \mid y) z e .
$$

Intuitively, if high-skilled people are offered a consumption-effort bundle $(d, e) \in \mathbb{R}_{+}^{2}$, then the level of utility they derive from this bundle is given as $u(d)-v(e)$. If all other countries offer such bundles that provide high-skilled people with a utility level of $y$, then the absolute mass of high-skilled people residing in the country will be $\alpha M(u(d)-v(e) \mid y)$, taking account of the fact that the proportion of high-skilled people in the world population is $\alpha$. Since low-skilled people are immobile, their absolute mass in the country remains $1-\alpha$. Hence, the left-hand side of (9) measures the total consumption of low- and high-skilled people, whereas the right-hand side gives the total amount of resources produced by high-skilled people. This way, (9) represents the aggregate resource constraint in the open-economy environment, requiring that total consumption not exceed total resources.

Given high-skilled people's symmetric outside option $y$ that they can attain in any other country, the Rawlsian government of country $i \in N$ seeks to provide low-skilled people with as much consumption as possible subject to incentive compatibility and

\footnotetext{
${ }^{12}$ I will return to the discussion of normative considerations in Section 9.
} 
aggregate feasibility by solving the following problem:

$$
\begin{aligned}
& \sup _{(c, d, e) \in \mathbb{R}_{+}^{3}} c \quad \text { such that } \\
& u(d)-v(e) \geq u(c), \\
&(1-\alpha) c \leq \leq \alpha M(u(d)-v(e) \mid y)(z e-d) .
\end{aligned}
$$

Definition 3 An allocation $\left(c^{*}, d^{*}, e^{*}\right) \in \mathbb{R}_{+}^{3}$ is a symmetric equilibrium if it solves the problem (10) for each country such that the outside option is given by $y=u\left(d^{*}\right)-v\left(e^{*}\right)$.

In other words, if the allocation $\left(c^{*}, d^{*}, e^{*}\right) \in \mathbb{R}_{+}^{3}$ is the best any one country can achieve according to the Rawlsian criterion when other countries offer the same allocation, then $\left(c^{*}, d^{*}, e^{*}\right)$ is said to be a symmetric equilibrium of the contest between the countries competing for human resources. ${ }^{13}$

Before characterizing the symmetric equilibrium, I give a justification for the definite article "the" in the previous clause of this sentence.

Proposition 2 There exists a unique symmetric equilibrium.

Proof See Appendix C.

\subsection{Characterization}

From now on, let $\left(c_{1}, d_{1}, e_{1}\right)$ denote the closed-economy benchmark allocation-whose existence and uniqueness has been established in Proposition 1-and let $\left(c_{n}, d_{n}, e_{n}\right)$ denote the symmetric equilibrium allocation-whose existence and uniqueness has been established in Proposition 2-in order to emphasize the dependence of the allocation on the number of countries. Moreover, let $y_{n} \equiv u\left(d_{n}\right)-v\left(e_{n}\right)$ denote the utility obtained by high-skilled workers in the symmetric equilibrium, which coincides with their outside option they can obtain in any particular country given symmetry. In addition, let

$$
m_{n} \equiv m\left(y_{n} \mid y_{n}\right)=n(n-1) \int_{-\infty}^{\infty} h(\psi)^{2}[1-H(\psi)]^{n-2} \mathrm{~d} \psi>0
$$

denote the partial derivative of the mass of any country's high-skilled population with respect to the utility level they are offered by that country's government in the symmetric equilibrium $-c f$. (8). Finally, define

$$
\bar{m} \equiv \frac{\alpha}{(1-\alpha) u^{\prime}\left(d_{1}\right) c_{1}} .
$$

The following proposition gives a useful characterization of the symmetric equilibrium and it shows also that its qualitative properties crucially depend on whether $m_{n}$ exceeds or falls short of the threshold $\bar{m}$ :

Proposition 3 The unique symmetric equilibrium $\left(c_{n}, d_{n}, e_{n}\right)$ satisfies the following properties:

\footnotetext{
${ }^{13}$ The analysis of asymmetric equilibria is omitted-in particular, I leave the question of whether any exists unanswered.
} 
(i) The budget constraint always binds: $(1-\alpha) c_{n}=\alpha\left(z e_{n}-d_{n}\right)$ and $c_{n}>0, d_{n}>0$, and $e_{n}>0$.

(ii) If $m_{n} \leq \bar{m}$, then the incentive-compatibility constraint is binding in the symmetric equilibrium allocation: $u\left(d_{n}\right)-v\left(e_{n}\right)=u\left(c_{n}\right)$, and this allocation coincides with the closedeconomy benchmark allocation: $\left(c_{n}, d_{n}, e_{n}\right)=\left(c_{1}, d_{1}, e_{1}\right)$.

(iii) If $m_{n}>\bar{m}$, then the incentive-compatibility constraint is slack in the symmetric equilibrium allocation: $u\left(d_{n}\right)-v\left(e_{n}\right)>u\left(c_{n}\right)$, and $c_{n}<c_{1}, d_{n}>d_{1}$, and $e_{n}<e_{1}$. Moreover, $\left(c_{n}, d_{n}, e_{n}\right)$ satisfies the following conditions:

$$
\begin{aligned}
\frac{v^{\prime}\left(e_{n}\right)}{u^{\prime}\left(d_{n}\right)} & =z, \\
m_{n} & =\frac{\alpha}{(1-\alpha) u^{\prime}\left(d_{n}\right) c_{n}}, \\
(1-\alpha) c_{n} & =\alpha\left(z e_{n}-d_{n}\right) .
\end{aligned}
$$

\section{Proof See Appendix D.}

The intuitive interpretation of the characterization of the symmetric equilibrium given by Proposition 3 is as follows. If, on the one hand, mobility of high-skilled workers at the margin is not too strong (as measured by the magnitude of $m_{n}$, the derivative of the mass of high-skilled people with respect to the level of welfare they can attain), then the closed-economy benchmark allocation prevails even in an open-economy environment in which governments compete with each other for the high-skilled workforce pool of the world economy.

If, on the other hand, high-skilled people's marginal propensity to migrate exceeds a certain threshold, then the closed-economy benchmark allocation is no longer offered by governments in the symmetric equilibrium. Instead, the resulting equilibrium allocation benefits the high-skilled (since they consume more and work less) and it becomes less generous towards the low-skilled (as they consume less) relative to the closed-economy benchmark. This threshold depends on how generous the closedeconomy allocation was towards low-skilled people before opening up the borders in the first place. If it was relatively generous (that is, $c_{1}$ was high and $d_{1}$ was low), then the resulting threshold $\bar{m}$ is low: the closed-economy benchmark becomes unsustainable even for low values of $m_{n}$. If, however, the closed-economy benchmark allocation was more frugal (meaning that $c_{1}$ was low and $d_{1}$ was high), then this allocation will be sustainable in an open economy even when high-skilled people are fairly mobile at the margin.

Once high-skilled people are so mobile that the closed-economy redistribution regime is no longer sustainable, governments begin to compete with each other for highskilled people. This is true in spite of the fact that the equilibrium mass of high-skilled population remains the same as in the closed economy-the sheer threat of losing high-skilled workers makes governments curtail income redistribution (cf. Lehmann et al., 2014). Correspondingly, the incentive-compatibility constraint becomes irrelevant: high-skilled people no longer want to imitate low-skilled people as welfare benefits become less attractive. It is (14) that becomes the relevant condition instead, showing that the more mobile high-skilled workers are at the margin (that is, the greater 
$m_{n}$ ), the worse off low-skilled people are as compared to high-skilled people (that is, the lower $c_{n}$ becomes relative to $d_{n}$ ).

The optimality condition (14) can be given a more detailed semi-formal quantitative interpretation as follows. Suppose that the government contemplates increasing the utility attained by high-skilled people by a small positive quantity $\Delta U_{h}>0$. Since $m_{n}$ is exactly the marginal sensitivity of the mass of high-skilled people with respect to their utility level in the symmetric equilibrium, this change attracts a mass of approximately $m_{n}\left(\Delta U_{h}\right)$ units of high-skilled people. The net amount of resources extracted from (or the implicit tax paid by) each high-skilled person is $z e_{n}-d_{n}$, and each unit extracted from each high-skilled person translates into $\alpha /(1-\alpha)$ extra units with which each low-skilled person can be provided. Hence, the approximate marginal benefit (in terms of extra consumption with which low-skilled people can be provided) of the change is given as

$$
m_{n}\left(\Delta U_{h}\right)\left(z e_{n}-d_{n}\right) \frac{\alpha}{1-\alpha}=m_{n} c_{n}\left(\Delta U_{h}\right),
$$

where the second expression follows from the aggregate resource constraint $(1-\alpha) c_{n}=\alpha\left(z e_{n}-d_{n}\right)$, which always holds with equality. However, increasing highskilled people's utility by $\Delta U_{h}$ units also has costs (in terms of consumption of the low-skilled), because endowing high-skilled people with a higher level of utility is possible only by making redistribution less generous. Since high-skilled people's utility in equilibrium is $u\left(d_{n}\right)-v\left(e_{n}\right)$, the change $\Delta U_{h}$ in the utility of high-skilled people is given approximately as

$$
\begin{aligned}
\Delta U_{h} & \approx u^{\prime}\left(d_{n}\right) \Delta d_{n}-v^{\prime}\left(e_{n}\right) \Delta e_{n}=u^{\prime}\left(d_{n}\right) \Delta d_{n}-z u^{\prime}\left(d_{n}\right) \Delta e_{n} \\
& =-u^{\prime}\left(d_{n}\right)\left(z \Delta e_{n}-\Delta d_{n}\right)=-u^{\prime}\left(d_{n}\right) \frac{1-\alpha}{\alpha} \Delta c_{n},
\end{aligned}
$$

where the equality $v^{\prime}\left(e_{n}\right)=z u^{\prime}\left(d_{n}\right)$ follows from either (3) or (13) and the last equality follows again from the aggregate resource constraint. Hence, after rearranging, the approximate marginal cost (in terms of low-skilled people's consumption) of increasing high-skilled people's utility by $\Delta U_{h}$ units is given as

$$
\frac{\alpha}{1-\alpha} \frac{1}{u^{\prime}\left(d_{n}\right)} \Delta U_{h}
$$

Comparing (16) and (17), the approximate net marginal benefit of increasing the utility of the high-skilled by $\Delta U_{h}>0$ units is given as

$$
\left(m_{n} c_{n}-\frac{\alpha}{(1-\alpha) u^{\prime}\left(d_{n}\right)}\right) \Delta U_{h}
$$

If this quantity is non-positive when $\left(c_{n}, d_{n}, e_{n}\right)=\left(c_{1}, d_{1}, e_{1}\right)$-that is, $m_{n} \leq \bar{m}$ - then the closed-economy benchmark allocation is an equilibrium, since governments optimally refrain from attracting more high-skilled people by increasing their utility at the margin. If, on the other hand, $m_{n}>\bar{m}$ (so that the closed-economy benchmark allocation is not sustainable), then governments compete with each other for high-skilled people up to the point at which the parenthesized first term of the expression in (18) 


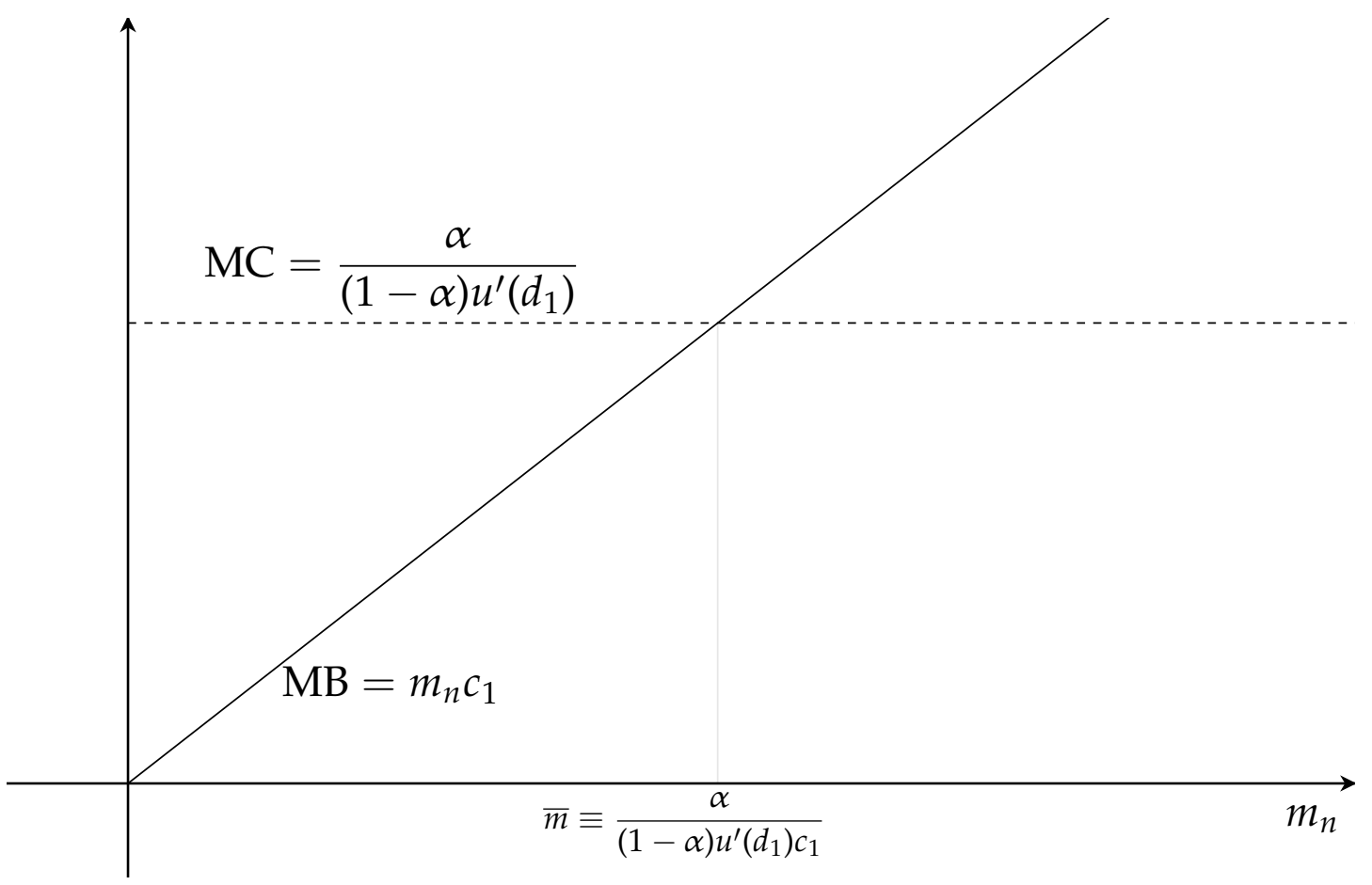

Figure 1: Marginal social benefit (solid line) and marginal social cost (dashed line) of increasing high-skilled people's utility by a marginal unit under the closed-economy allocation $\left(c_{1}, d_{1}, e_{1}\right)$, given as functions of the marginal sensitivity of the mass of high-skilled people with respect to their utility level in the presence of $n$ countries. The marginal benefit (MB) is $m_{n} c_{1}$ and the marginal cost (MC) is $\alpha\left[(1-\alpha) u^{\prime}\left(d_{1}\right)\right]^{-1}$. If $m_{n}$ falls short of the threshold $\bar{m}$, then the marginal cost of attracting high-skilled immigrants exceeds the marginal benefit, implying that the closed-economy allocation remains an equilibrium. If $m_{n}>\bar{m}$, then MB $>$ MC under the closed-economy allocation, which therefore ceases to be an equilibrium. Instead, countries strive to attract more immigrants and adjust the allocations they offer until the marginal benefit of attracting more high-skilled foreigners equals the marginal cost, the equilibrium condition for which is given by (14).

vanishes-hence (14). See Figure 1 for a graphical representation of this intuitive explanation.

The comparison of the marginal benefits (16) and the marginal costs (17) of making high-skilled people better off illustrates the trade-off governments are faced with when the aggregate resource constraint is endogenous. If the mass of high-skilled people is relatively sensitive to the utility level they attain, then the benefits of attracting them exceed the costs, rendering governments' incentives to compete for them stronger. This effect ultimately hurts governments' redistributive goals. If, on the other hand, the sensitivity of the mass of high-skilled population is relatively low, then the costs (in terms of the generosity of redistribution) of attracting them exceed the benefits of a larger high-skilled workforce. Correspondingly, competition between governments for high-skilled workers will be weak-or even non-existent, in which case the closedeconomy redistribution scheme continues to prevail even with the borders being open. 
Additionally, efficiency continues to require that high-skilled people's labor-effort supply not be distorted at the margin also under the frugal redistribution regimehence (13).

\section{Comparative Statics}

In this section, I analyze how income redistribution in the symmetric equilibrium depends on the number of countries in the world. Such an analysis also begs the question: What happens asymptotically to redistribution as the number of countries grows to infinity? Moreover, the implications of high-skilled people becoming extremely mobile in a world economy consisting of a fixed finite number of countries are also examined.

\subsection{Number of Countries}

I firstly show that the marginal sensitivity of the mass of high-skilled people with respect to their welfare option in equilibrium increases with the number of countries.

Lemma 4 If $n^{\prime}>n^{\prime \prime}$ (where $n^{\prime}, n^{\prime \prime} \geq 2$ are positive integers), then $m_{n^{\prime}} \geq m_{n^{\prime \prime}}$.

Proof See Appendix E.

The next proposition shows that redistribution becomes less generous as the number of countries grows.

Proposition 4 Let $n^{\prime}>n^{\prime \prime}$ and let $\left(c_{n^{\prime}}, d_{n^{\prime}}, e_{n^{\prime}}\right)$ and $\left(c_{n^{\prime \prime}}, d_{n^{\prime \prime}}, e_{n^{\prime \prime}}\right)$ denote the corresponding allocations in the respective symmetric equilibria. Then, $c_{n^{\prime}} \leq c_{n^{\prime \prime}}, d_{n^{\prime}} \geq d_{n^{\prime \prime}}$, and $e_{n^{\prime}} \leq e_{n^{\prime \prime}}$.

Proof See Appendix E.

\subsection{Asymptotics}

Suppose now that the number of countries in the world increases without bound. How much — if any at all—redistribution is possible in the limit? It turns out that the asymptotic properties of the symmetric equilibrium depend crucially on the slope of the density function of location preferences on the far left side of its support. In order to operationalize this dependence, I introduce the following definition.

Definition 4 The distribution of location preferences is said to have mildly increasing left tail if

$$
\lim _{\psi \rightarrow-\infty} \frac{h^{\prime}(\psi)}{h(\psi)}<\infty
$$

Recall that the probability density function $h$ has been assumed to be log-concave. This implies that the derivative of $\log \circ h$, which is given as $h^{\prime} / h$, is non-increasing. Hence, the limit in (19) exists (and is possibly infinite) and $h$ satisfies the condition of mildly increasing left tail precisely when this limit is finite. Examples of probability distributions satisfying this criterion and those failing to satisfy it will be discussed in Section 7. 
Lemma 4 implies that the marginal sensitivity of the mass of high-skilled people with respect to their welfare option in equilibrium is a non-decreasing function of the number of countries. Consequently, it either becomes bounded or diverges to infinity as the number of countries grows without bound. The following lemma reveals that the asymptotic behavior of $m_{n}$ is completely determined by whether the distribution of location preferences has mildly increasing left tail or not.

Proposition 5 The distribution of location preferences has mildly increasing left tail if and only if

$$
\lim _{n \rightarrow \infty} m_{n}<\infty
$$

\section{Proof See Appendix E.}

Recall from Proposition 3 that there exists a threshold $\bar{m}$, defined in (12), such that if $m_{n} \leq \bar{m}$, then the symmetric equilibrium allocation is the same as the closed-economy benchmark allocation, and if $m_{n}>\bar{m}$, then redistribution in the symmetric equilibrium is less generous than in the closed economy. Remember also that $(0, z \bar{e}, \bar{e})$ is the laissezfaire allocation that is offered in the absence of governments, where $\bar{e}>0$ is the unique solution to (1). The following proposition shows that the statistical properties of the distribution of location preferences translate into stark economic implications.

Proposition 6 Suppose that the number of countries grows without bound and let $m_{\infty} \equiv$ $\lim _{n \rightarrow \infty} m_{n}$. Then, the sequence of allocations corresponding to the sequence of symmetric equilibria $\left(c_{n}, d_{n}, e_{n}\right)_{n=2}^{\infty}$ converges to some $\left(c_{\infty}, d_{\infty}, e_{\infty}\right) \in \mathbb{R}_{+}^{3}$. This asymptotic allocation satisfies the following properties:

(i) If the distribution of location preferences has mildly increasing left tail and $m_{\infty} \leq \bar{m}$, then the asymptotic allocation coincides with the closed-economy benchmark allocation

$$
\left(c_{\infty}, d_{\infty}, e_{\infty}\right)=\left(c_{1}, d_{1}, e_{1}\right)
$$

(ii) If the distribution of location preferences has mildly increasing left tail and $m_{\infty}>\bar{m}$, then the asymptotic allocation satisfies

$$
\begin{aligned}
\frac{v^{\prime}\left(e_{\infty}\right)}{u^{\prime}\left(d_{\infty}\right)} & =z, \\
m_{\infty} & =\frac{\alpha}{(1-\alpha) u^{\prime}\left(d_{\infty}\right) c_{\infty}}, \\
(1-\alpha) c_{\infty} & =\alpha\left(z e_{\infty}-d_{\infty}\right),
\end{aligned}
$$

and $c_{\infty} \in\left(0, c_{1}\right), d_{\infty} \in\left(d_{1}, z \bar{e}\right)$, and $e_{\infty} \in\left(\bar{e}, e_{1}\right)$.

(iii) If the distribution of location preferences does not have mildly increasing left tail, then the asymptotic allocation coincides with the laissez-faire allocation:

$$
\left(c_{\infty}, d_{\infty}, e_{\infty}\right)=(0, z \bar{e}, \bar{e})
$$


Proof See Appendix E.

In order to appreciate the intuitive content of Proposition 6, it is useful to reconsider the decomposition of $m_{n}$ discussed in Subsection 4.2:

$$
\begin{aligned}
m_{n} & =\frac{1}{n} m_{n}+\frac{n-1}{n} m_{n} \\
& =\underbrace{\int_{-\infty}^{\infty} h^{\prime}(\psi)[1-H(\psi)]^{n-1} \mathrm{~d} \psi}_{\text {retention effect }}+\underbrace{(n-1) \int_{-\infty}^{\infty} h^{\prime}(\psi)[1-H(\psi)]^{n-1} \mathrm{~d} \psi,}_{\text {attraction effect }}
\end{aligned}
$$

where the second line follows from (51) in the proof of Lemma 4. It is not difficult to see that the retention effect always vanishes asymptotically. ${ }^{14}$ Intuitively, as there are more and more countries in world economy, it becomes ever less likely that a high-skilled native of any one particular country will find her homeland more attractive than all of the other countries. Consequently, no country can retain its original high-skilled population as the world economy grows large. Therefore, the asymptotic marginal sensitivity of the mass of high-skilled people to their utility option is fully determined by the attraction effect-governments' ability to populate their countries with high-skilled people from elsewhere. In other words, as the retention effect vanishes with the number of countries growing without bound, the strategic interaction between the world's governments is completely driven by the attraction effect asymptotically.

If the distribution of location preferences fails to exhibit mildly increasing left tail, then Proposition 5 implies that $m_{n}$, and hence the attraction effect, diverge. A rapidly increasing left tail means that the slope of the density function $h^{\prime}(\psi)$ is locally very large as compared to $h(\psi)$ for very large negative values of $\psi$. Intuitively, if the slope of $h$ increases very rapidly relative to $h$ on the left tail of the distribution, then, at the margin, each country can reap large masses of human resources embodied by foreign high-skilled workers by offering them marginally better welfare options, provided that the location preferences of those people are located very far to the left of the tail. ${ }^{15}$ Moreover, this effect becomes stronger as more countries appear, because the "pool" of competitors from which any one particular country can attract high-skilled people with location preferences on the left tail becomes larger-that is, the more countries

${ }^{14}$ Indeed, recall from the proof of Lemma 1 that

$$
\lim _{\psi \rightarrow-\infty} h(\psi)=\lim _{\psi \rightarrow \infty} h(\psi)=0
$$

and that the sign of $h^{\prime}$ is non-increasing. This readily entails that $h^{\prime}$ is absolutely integrable. Since the value of the function $\psi \mapsto[1-H(\psi)]^{n-1}$ never exceeds unity and it converges pointwise to the identically zero function as $n \rightarrow \infty$, Lebesgue's dominated convergence theorem implies that

$$
\lim _{n \rightarrow \infty}\left\{\int_{-\infty}^{\infty} h^{\prime}(\psi)[1-H(\psi)]^{n-1} \mathrm{~d} \psi\right\}=\int_{-\infty}^{\infty} \lim _{n \rightarrow \infty}\left\{h^{\prime}(\psi)[1-H(\psi)]^{n-1}\right\} \mathrm{d} \psi=0 .
$$

${ }^{15}$ Remember that $\psi_{k j}<\psi_{k i}$ means that a person initially living in country $k$ prefers country $j$ to country $i$. 
there are, the more left tails each can attract people from. This tends to intensify competition between governments for human resources as the number of countries grows. In the limit, this effect becomes so strong that countries wind up engaging in a "race to the bottom" with each other for high-skilled workers, and the competition for the multitude of left tails becomes so fierce that any kind of redistribution towards low-skilled people becomes asymptotically impossible. Hence, the laissez-faire allocation prevails in the limit.

If, however, the distribution of location preferences has mildly increasing left tail, then the effect mentioned supra becomes limited even asymptotically, as the marginal mass of high-skilled workers that governments can attract by curtailing redistribution remains bounded even on the far-left tail of the distribution of location preferences. Hence, in spite of the fact that the "pool" of left tails grows as more countries appear, the desirability of attracting high-skilled people from those left tails remains limited, so that competition between governments remains moderate even in the limit. If the attraction effect converges to a large but finite value, then the asymptotic outcome is an allocation that still provides some redistribution, even though not as much as the closed-economy benchmark. Into the bargain, if the attraction effect remains small asymptotically, then there is essentially no competition between countries for high-skilled workers, and the closed-economy benchmark remains an equilibrium outcome-even asymptotically!

\subsection{Perfect Mobility}

For now, suppose that the number of countries is fixed at $n \in \mathbb{N}$ (with $n \geq 2$ ). What happens to redistribution in the limit as people become perfectly mobile? To answer this question, I first provide an operationalization of perfect mobility. Consider a sequence of probability density functions $\left(h_{k}\right)_{k \in \mathbb{N}}$ that all satisfy Assumption 1 and suppose that the sequence of probability distributions of location preferences represented by this sequence of density functions converges weakly to the point mass at 0 . This means that the sequence of the corresponding cumulative distribution functions $\left(H_{k}\right)_{k \in \mathbb{N}}$ satisfies

$$
\lim _{k \rightarrow \infty} H_{k}(\psi)= \begin{cases}0 & \text { if } \psi<0 \\ 1 & \text { if } \psi>0\end{cases}
$$

Intuitively, as $k \rightarrow \infty$, high-skilled people's idiosyncratic location preferences gradually disappear and they care about where they live only in so far as their pure economic welfare-embodied by the consumption-effort combination they obtain-is concerned.

For any $k \in \mathbb{N}$, let $m_{n, k}$ denote the marginal sensitivity of the mass of high-skilled people when the distribution of location preferences is determined by the probability density function $h_{k}$ :

$$
m_{n, k} \equiv n(n-1) \int_{-\infty}^{\infty} h_{k}(\psi)^{2}\left[1-H_{k}(\psi)\right]^{n-2} \mathrm{~d} \psi,
$$

and let $\left(c_{n, k}, d_{n, k}, e_{n, k}\right)$ denote the allocation in the corresponding symmetric equilibrium. 
Proposition 7 For any fixed $n \in \mathbb{N}(n \geq 2), \lim _{k \rightarrow \infty} m_{n, k}=\infty$ and the sequence of symmetric equilibrium allocations converges to the laissez-faire allocation:

$$
\lim _{k \rightarrow \infty}\left(c_{n, k}, d_{n, k}, e_{n, k}\right)=(0, z \bar{e}, \bar{e})
$$

Proof See Appendix E.

Proposition 7 states that as high-skilled people's location preferences approach perfect mobility, redistribution collapses in the limit-even when there are only two countries! This is because with a more mobile population of high-skilled workers, it becomes ever more profitable-at the margin-for each country both to retain their own high-skilled population and to attract skilled workers from elsewhere. In the limit, competition between countries for labor effort becomes so fierce that no resources can be extracted from high-skilled people whatsoever in order to support low-skilled ones. This asymptotic phenomenon is reminiscent of Bertrand competition in industrialorganization models: With no idiosyncratic consumer tastes, the presence of even a single competitor can destroy all of the incumbent firm's market power.

\section{Examples}

In this section, I illustrate the theoretical results established supra by means of several numerical examples. I consider two classical families of probability distributions of location preferences. First, consider the logistic distribution with mean zero and scale parameter $\sigma>0:^{16}$

$$
\begin{aligned}
h(\psi) & \equiv \frac{\exp (-\psi / \sigma)}{\sigma[1+\exp (-\psi / \sigma)]^{2}} \quad \text { for all } \psi \in \mathbb{R}, \\
H(\psi) & \equiv \frac{1}{1+\exp (-\psi / \sigma)} \quad \text { for all } \psi \in \mathbb{R} .
\end{aligned}
$$

It is not difficult to check that the logistic distribution satisfies Assumption 1. Moreover,

$$
\frac{h^{\prime}(\psi)}{h(\psi)}=-\frac{1}{\sigma} \frac{1-\exp (-\psi / \sigma)}{1+\exp (-\psi / \sigma)} \rightarrow \frac{1}{\sigma}<\infty \quad \text { as } \psi \rightarrow-\infty,
$$

so that $h$ has mildly increasing left tail. By Proposition 5, it follows that $\lim _{n \rightarrow \infty} m_{n}<$ $\infty$. In fact, the marginal sensitivity of the mass of high-skilled people can be explicitly computed:

$$
m_{n}=\frac{1}{\sigma} \frac{n-1}{n+1} \quad \text { for any } n \in \mathbb{N}, n \geq 2
$$

Therefore, $m_{\infty} \equiv \lim _{n \rightarrow \infty} m_{n}=1 / \sigma$.

\footnotetext{
${ }^{16}$ This scale parameter is closely related, but not identical, to the standard deviation of the logistic distribution. In fact, its variance is given as $\sigma^{2} \pi^{2} / 3$.
} 
Second, consider the normal distribution with mean zero and standard deviation $\sigma>0$ :

$$
h(\psi) \equiv \frac{1}{\sigma \sqrt{2 \pi}} \exp \left(-\frac{\psi^{2}}{2 \sigma^{2}}\right) \quad \text { for all } \psi \in \mathbb{R}
$$

While I have not been able to obtain a closed-formed expression for $m_{n}$, the normal distribution does not exhibit mildly increasing left tail because

$$
\lim _{\psi \rightarrow-\infty} \frac{h^{\prime}(\psi)}{h(\psi)}=\lim _{\psi \rightarrow-\infty}\left\{-\frac{\psi}{\sigma^{2}}\right\}=\infty
$$

Hence, Proposition 5 implies that $m_{\infty}=\infty$ for the normal distribution. It is apparent also that the normal distribution satisfies Assumption 1, too.

In what follows, I will consider three specific distributions of location preferences: (i) the logistic distribution with $\sigma=1$; (ii) the logistic distribution with $\sigma=2$; and (iii) the normal distribution with $\sigma=1 / 5 .{ }^{17}$ For the rest of this section, assume also that

$$
\begin{aligned}
& u(c) \equiv 7 \log (c+1) \quad \text { for all } c \geq 0, \\
& v(e) \equiv \frac{e^{2}}{10} \text { for all } e \geq 0 .
\end{aligned}
$$

\begin{tabular}{|c|c|c|c|}
\hline \multicolumn{4}{|c|}{ Laissez-faire allocation } \\
\hline$=0$ & $\bar{d}=5.437$ & $\bar{e}=5.437$ & \\
\hline \multicolumn{4}{|c|}{ Closed-economy benchmark allocation } \\
\hline$c_{1}=2.452$ & $d_{1}=4.804$ & $e_{1}=6.030$ & $\bar{m}=0.676$ \\
\hline \multicolumn{4}{|c|}{ Logistic location preferences, $\sigma=1$} \\
\hline$c_{\infty}=1.711$ & $d_{\infty}=4.989$ & $e_{\infty}=5.844$ & $m_{\infty}=1$ \\
\hline \multicolumn{4}{|c|}{ Logistic location preferences, $\sigma=2$} \\
\hline$c_{\infty}=2.452$ & $d_{\infty}=4.804$ & $e_{\infty}=6.030$ & $m_{\infty}=1 / 2$ \\
\hline \multicolumn{4}{|c|}{ Normal location preferences, $\sigma=1 / 5$} \\
\hline$c_{\infty}=0$ & $d_{\infty}=5.437$ & $e_{\infty}=5.437$ & $m_{\infty}=\infty$ \\
\hline
\end{tabular}

It is easy to check that this utility specification obeys Assumption 2. Moreover, let $z \equiv 1$ and $\alpha \equiv 2 / 3$, meaning that two-thirds of the population are high-skilled. All of the results infra are reported up to three-digit accuracy.

Table 1: Summary of numerical examples.

Table 1 summarizes all the numerical results. ${ }^{18}$ Observe that high-skilled people consume less and work more in the closed-economy benchmark than in the laissez-faire economy in order for the government to be able to support low-skilled people.

${ }^{17}$ These scale parameters are chosen merely for expositional convenience. In particular, any 

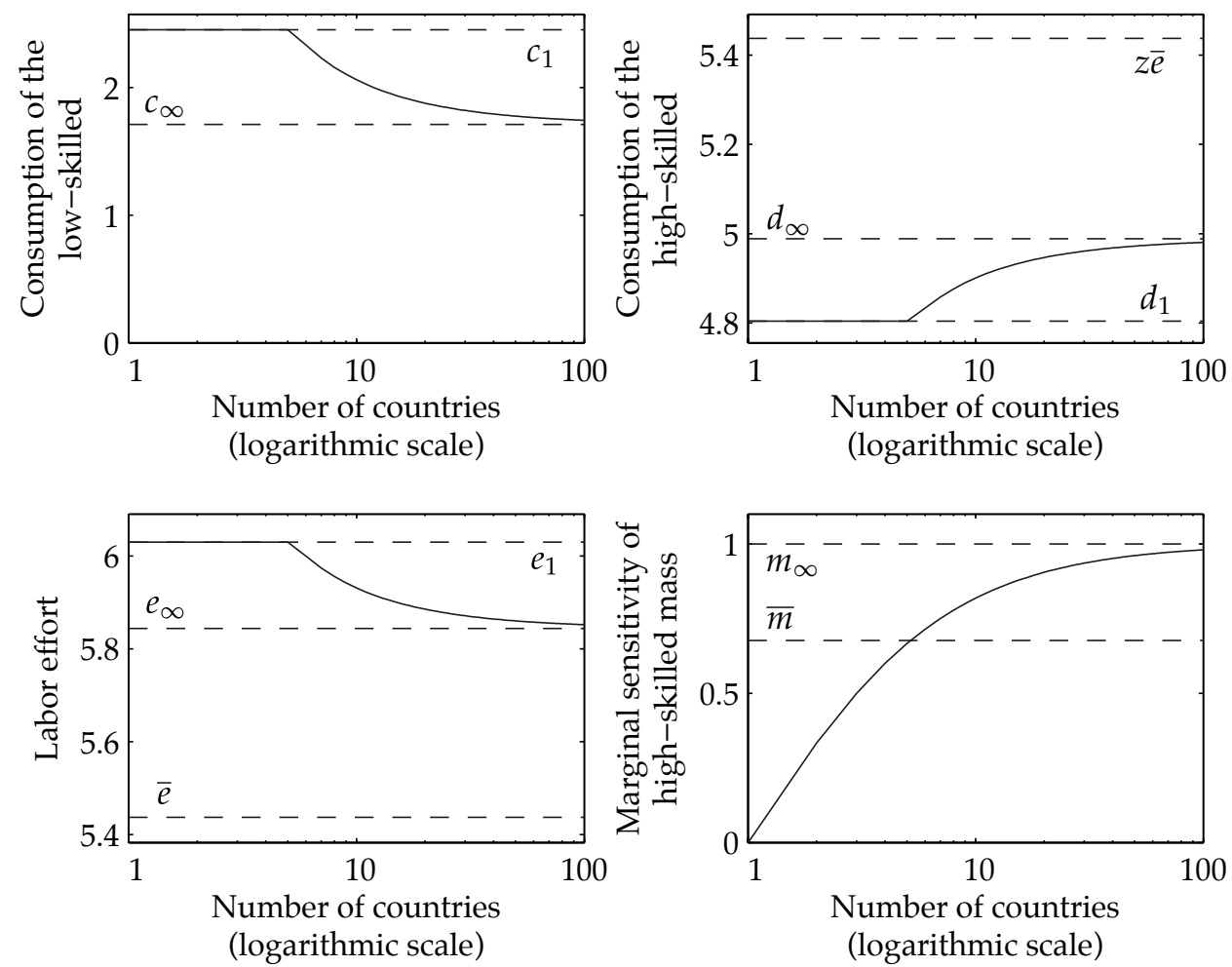

Figure 2: Sequence of symmetric equilibria when the distribution of location preferences is logistic with scale parameter $\sigma=1$.

Consider first the case in which the distribution of location preferences is logistic with scale parameter $\sigma=1$. The sequence of equilibria as the number of countries increases is depicted in Figure 2. The threshold value of the marginal sensitivity of the mass of the high-skilled $\bar{m}$, above which the closed-economy benchmark allocation is not sustainable [see Proposition 3 and (12)], is equal to 0.676. From (25), it follows that $m_{n}=(n-1) /(n+1)$, so that the closed-economy benchmark allocation remains an equilibrium if and only $m_{n} \leq \bar{m}$, or $n \leq 5$, as can be easily computed. Once more than five countries are present, the closed-economy benchmark allocation becomes un-

mean-zero normal distribution with positive standard deviation would lead to the same qualitative conclusions.

${ }^{18}$ The laissez-faire allocation, denoted as $(\bar{c}, \bar{d}, \bar{e}) \equiv(0, z \bar{e}, \bar{e})$, can be computed from (1). The closed-economy benchmark allocation can be computed using Proposition 1 . The threshold value of the marginal sensitivity of the mass of the high-skilled $\bar{m}$, above which threshold the closed-economy benchmark allocation is not sustainable in equilibrium, can be computed from (12). The asymptotic values of $m_{\infty}$ follow from (25) for the logistic distribution and, for the normal distribution, from the fact that this distribution does not have mildly increasing left tail. Finally, the asymptotic equilibrium allocations can be determined using Proposition 6. 
sustainable in the symmetric equilibrium and redistribution becomes less generous. However, since $m_{\infty}=1$ is finite, Proposition 6 implies that the asymptotic equilibrium allocation $\left(c_{\infty}, d_{\infty}, e_{\infty}\right)$ is intermediate between the closed-economy benchmark allocation $\left(c_{1}, d_{1}, e_{1}\right)$ and the laissez-faire allocation $(0, z \bar{e}, \bar{e}) .{ }^{19}$
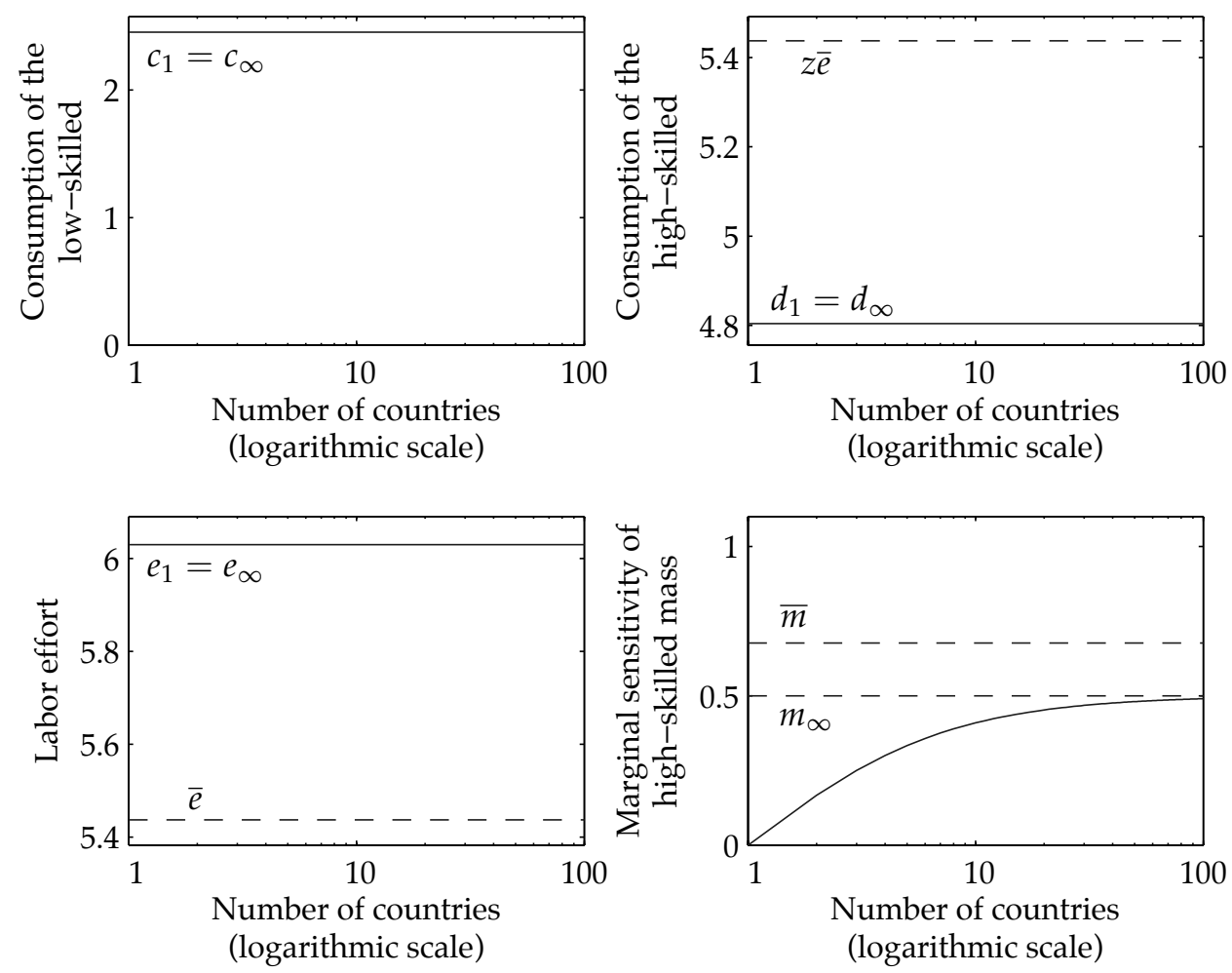

Figure 3: Sequence of symmetric equilibria when the distribution of location preferences is logistic with scale parameter $\sigma=2$.

Next, suppose that the distribution of location preferences is logistic with scale parameter $\sigma=2$. Observe that

$$
m_{\infty} \equiv \lim _{n \rightarrow \infty}\left\{\frac{1}{\sigma} \frac{n-1}{n+1}\right\}=\frac{1}{2} .
$$

Given that $\bar{m}=0.676$ and the sequence $\left(m_{n}\right)_{n=2}^{\infty}$ is non-decreasing by Lemma 4 , it follows that the closed-economy benchmark allocation is sustainable as a symmetric equilibrium for any number of countries. Hence, competition between governments for high-skilled workers does not affect redistribution at all! This outcome is illustrated in Figure 3.

If, however, the distribution of location preferences is normal (with standard deviation $\sigma=1 / 5$ ), then the fact that this distribution fails to exhibit mildly increasing left ${ }^{19}$ The implicit tax rate $1-d /(z e)$ on high-skilled people's gross income is approximately $15 \%$
in the asymptotic economy, as compared to $20 \%$ in the closed economy. 

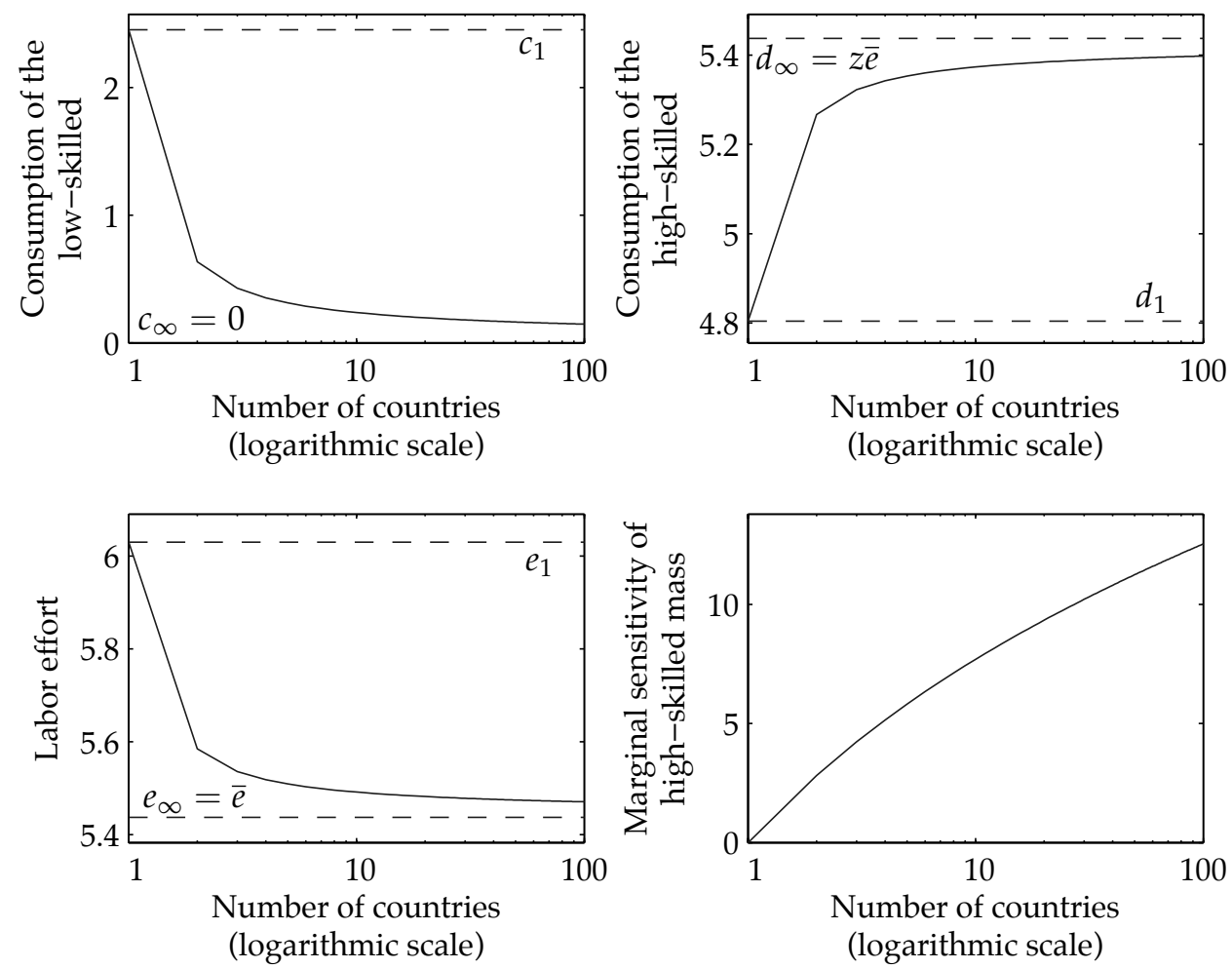

Figure 4: Sequence of symmetric equilibria when the distribution of location preferences is normal with standard deviation $\sigma=1 / 5$.

tail entails that the sequence $\left(m_{n}\right)_{n=2}^{\infty}$ diverges (see Proposition 5). Correspondingly, the sequence of symmetric equilibria converges to the laissez-faire allocation by Proposition 6 and redistribution collapses in the limit-see Figure 4.

This series of examples highlights the fact that the extent to which redistribution is possible with governments competing with each other for skilled labor crucially depends on the minute details of the distributional assumptions imposed on skilled workers' location preferences. Indeed, even distributions seemingly very similar, as the normal and the logistic distributions are, may lead to diametrically opposed conclusions as to the asymptotic sustainability of income redistribution.

As a final example, consider the implications of asymptotically perfect mobility. Suppose that the number of countries is fixed at some $n \geq 2$. Consider a sequence of logistic distributions of location preferences $\left(h_{k}\right)_{k=1}^{\infty}$ indexed by a sequence of positive scale parameters $\left(\sigma_{k}\right)_{k=1}^{\infty}$. Specifically, assume that

$$
\begin{aligned}
h_{k}(\psi) & \equiv \frac{\exp \left(-\psi / \sigma_{k}\right)}{\sigma_{k}\left[1+\exp \left(-\psi / \sigma_{k}\right)\right]^{2}} \quad \text { for all } \psi \in \mathbb{R} \text { and } k \in \mathbb{N}, \\
H_{k}(\psi) & \equiv \frac{1}{1+\exp \left(-\psi / \sigma_{k}\right)} \quad \text { for all } \psi \in \mathbb{R} \text { and } k \in \mathbb{N},
\end{aligned}
$$



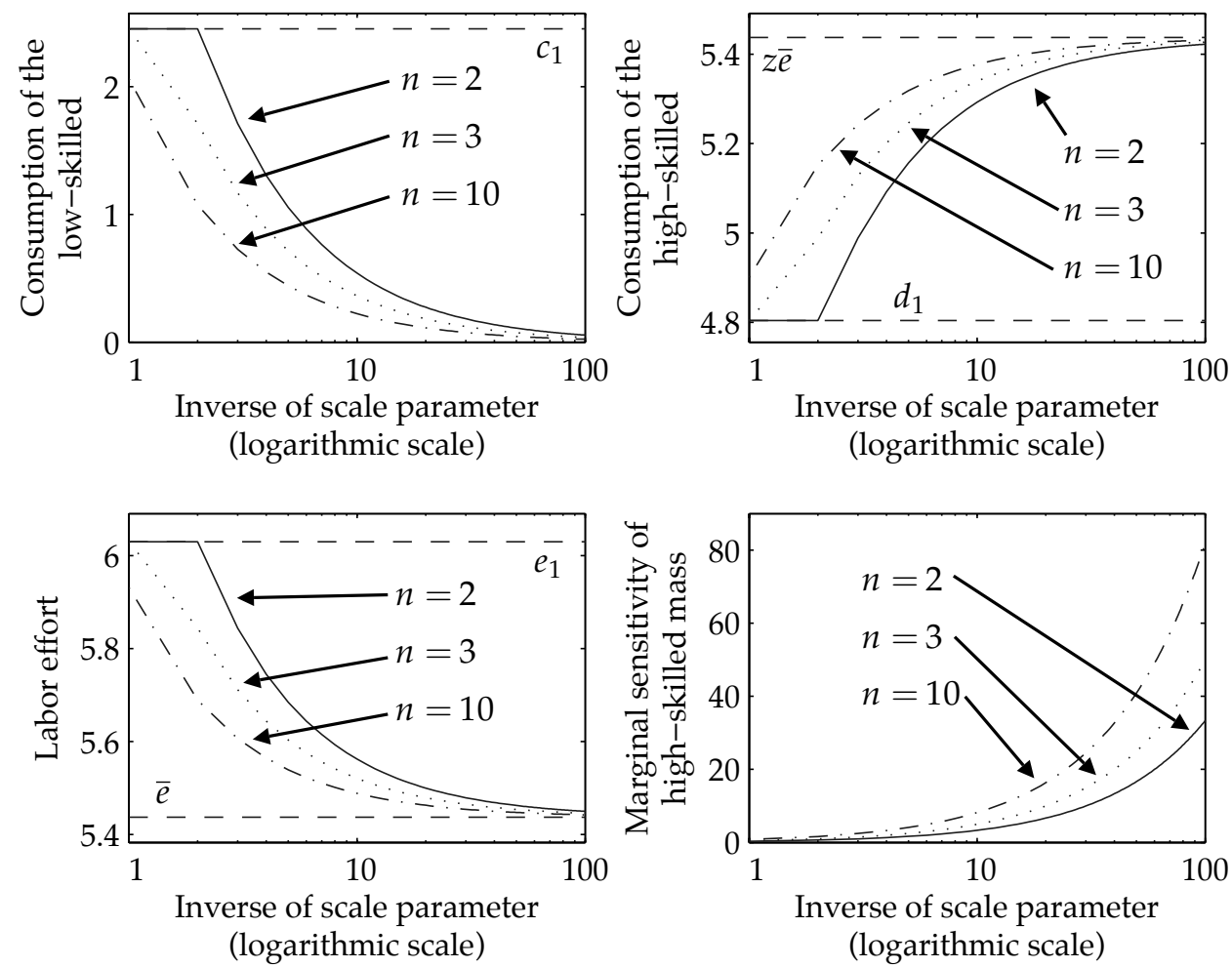

Figure 5: Sequence of symmetric equilibria when the distribution of location preferences is logistic and converges weakly to the point mass at zero. Solid, dotted, and dash-dotted lines correspond to equilibria in the presence of two, three, and ten countries, respectively.

where $\sigma_{k} \equiv 1 / k$. This means that the variance of the distribution asymptotically vanishes-cf. n. 16-and it is easy to see that the sequence of probability distributions determined by $\left(h_{k}\right)_{k=1}^{\infty}$ converges weakly to the point mass at zero. By Proposition 7, this implies that the marginal sensitivity of the mass of high-skilled people diverges and the corresponding sequence of symmetric equilibria converges to the laissez-faire allocation. This phenomenon is highlighted in Figure 5, where the asymptotic behavior of the sequence of equilibria as high-skilled people become infinitely mobile is depicted for $n=2, n=3$, and $n=10$. Clearly, redistribution collapses in the limit in all casesalbeit more slowly when there are fewer countries.

\section{Operationalization of Location Preferences}

The structure of the distribution of location preferences introduced in Subsection 2.2 is admittedly highly stylized. In this section, I offer a way of translating them into broadly interpreted migration costs, which may facilitate empirical applications of the theoretical model in so far as migration costs are easier to measure than the underlying 
structure of location preferences. It is also in this section that I discuss the implications of introducing home bias.

\subsection{Location Preferences and Migration Costs}

For any pair of countries $(i, j) \in N^{2}$, denote $C_{i j} \equiv \psi_{i j}-\psi_{i i}$. As argued in Subsection 2.2 , the quantity $C_{i j}$ is a measure of the relative preference of staying in country $i$ as compared to moving to country $j$. As such, it can be interpreted as migration costs in a broad sense, encompassing monetary, psychological, and administrative costs of migrating from country $i$ to country $j$, as well as capturing climatic considerations and geographic, linguistic, or cultural proximities between different countries.

For a given country $i \in N$, the joint distribution of migration costs $\left(C_{i j}\right)_{j \in N \backslash\{i\}}$ can be easily recovered from the joint distribution of location preferences $\left(\psi_{i j}\right)_{j \in N}$. Without loss of generality, let $i=1$. Then, one has ${ }^{20}$

$$
\left[\begin{array}{c}
\psi_{11} \\
C_{12} \\
C_{13} \\
\vdots \\
C_{1 n}
\end{array}\right]=\underbrace{\left[\begin{array}{rr}
1 & \mathbf{0} \\
-\mathbf{1} & \mathbf{I}
\end{array}\right]}_{\equiv \mathbf{A}}\left[\begin{array}{c}
\psi_{11} \\
\psi_{12} \\
\psi_{13} \\
\vdots \\
\psi_{1 n}
\end{array}\right],
$$

where $\mathbf{0}$ is a row vector of $n-1$ entries of zero, $\mathbf{1}$ is a column vector of $n-1$ entries of unity, and $\mathbf{I}$ is the identity matrix of $n-1$ rows and $n-1$ columns. Note that the matrix $\mathbf{A}$ is invertible and

$$
\mathbf{A}^{-1}=\left[\begin{array}{ll}
1 & \mathbf{0} \\
\mathbf{1} & \mathbf{I}
\end{array}\right]
$$

Let $\widetilde{h}$ denote the joint probability density function of the random vector $\left(\psi_{11}, C_{12}, C_{13}, \ldots, C_{1 n}\right)$. Given that the joint probability density function of the random vector $\left(\psi_{11}, \psi_{12}, \psi_{13}, \ldots, \psi_{1 n}\right)$ is given by $\prod_{j=1}^{n} h\left(\psi_{1 j}\right)$, a simple change of variables implies that

$$
\begin{aligned}
& \tilde{h}\left(\psi_{11}, C_{12}, C_{13}, \ldots, C_{1 n}\right) \\
= & h\left(\psi_{11}\right) \times h\left(C_{12}+\psi_{11}\right) \times h\left(C_{13}+\psi_{11}\right) \times \ldots \times h\left(C_{1 n}+\psi_{11}\right) \times \underbrace{\left|\operatorname{det}\left(\mathbf{A}^{-1}\right)\right|}_{=1} .
\end{aligned}
$$

Hence, the joint probability density function of migration costs $\left(C_{12}, C_{13}, \ldots, C_{1 n}\right)$, denoted as $\widehat{h}$, can be computed as follows:

$$
\begin{aligned}
\widehat{h}\left(C_{12}, C_{13}, \ldots, C_{1 n}\right) & =\int \tilde{h}\left(\psi_{11}, C_{12}, C_{13}, \ldots, C_{1 n}\right) \mathrm{d} \psi_{11} \\
& =\int h\left(\psi_{11}\right) \times \prod_{j=2}^{n} h\left(C_{1 j}+\psi_{11}\right) \mathrm{d} \psi_{11} .
\end{aligned}
$$

\footnotetext{
${ }^{20}$ Observe that the cost of staying in the home country is normalized to zero: $C_{11}=0$.
} 
Empirically, the migration-cost profile $\left(C_{1 j}\right)_{j=2}^{n}$ can be measured by asking a highskilled person originally residing in country 1 how much compensation she requires or how much she is willing to pay in exchange for moving to another country $j$, provided that she faces the same economic opportunities (that is, she is offered the same consumption-effort menu) in both countries. This would yield an empirical estimate of $\widehat{h}$, the joint probability density function of the migration costs $\left(C_{1 j}\right)_{j=2}^{n}$. Equation (26), in turn, provides a way finding the probability density function $h$ of the underlying idiosyncratic location preferences that generates the empirically observed joint density $\widehat{h}$ of migration costs.

At any rate, the assumption that idiosyncratic location preferences are identically and independently distributed implies that the migration costs from a given source country to any pair of different destination countries are positively correlated, with a correlation coefficient of $1 / 2$. To see this, fix any pair of countries $(j, k) \in\{2, \ldots, n\}^{2}$ with $j \neq k$ and assume that the density function $h$ of location preferences admits a finite positive variance $\sigma^{2} \in(0, \infty)$. Then,

$$
\operatorname{Var}\left(C_{1 j}\right)=\operatorname{Var}\left(\psi_{1 j}-\psi_{11}\right)=\operatorname{Var}\left(\psi_{1 j}\right)+\operatorname{Var}\left(\psi_{11}\right)-\underbrace{2 \operatorname{Cov}\left(\psi_{1 j}, \psi_{11}\right)}_{=0}=2 \sigma^{2},
$$

and, similarly, $\operatorname{Var}\left(C_{1 k}\right)=2 \sigma^{2}$. Moreover,

$$
\operatorname{Cov}\left(C_{1 j}, C_{1 k}\right)=\operatorname{Cov}\left(\psi_{1 j}-\psi_{11}, \psi_{1 k}-\psi_{11}\right)=\operatorname{Cov}\left(\psi_{11}, \psi_{11}\right)=\operatorname{Var}\left(\psi_{11}\right)=\sigma^{2} .
$$

Hence, the correlation coefficient between $C_{1 j}$ and $C_{1 k}$ is given as

$$
\frac{\operatorname{Cov}\left(C_{1 j}, C_{1 k}\right)}{\sqrt{\operatorname{Var}\left(C_{1 j}\right) \operatorname{Var}\left(C_{1 k}\right)}}=\frac{1}{2} .
$$

Intuitively, if a given high-skilled person is reluctant to move to any given foreign country, idiosyncratic reasons on the personal level (unwillingness to leave family behind, risk aversion, insufficient funds, inadmissibility to enter, etc.) make it likelier that she is reluctant to move abroad at all, which renders correlation between migration costs positive. On the other hand, destination countries may have different characteristics in terms of distance, language, culture, and climate, which prevents idiosyncratic migration costs (broadly interpreted) from being perfectly correlated across potential destinations. The estimation strategy outlined supra may help assess whether the prediction of the correlation coefficient between the costs of migrating to any pair of destination countries being one-half is empirically reasonable and sustained by the data. ${ }^{21}$

\subsection{Home Bias}

The assumptions imposed on the distribution of location preferences in Subsection 2.2 imply that the mean of $\psi_{i j}-\psi_{i i}$, the quantity representing the costs of migrating from country $i$ to country $j$, vanishes for any pair of countries $(i, j) \in N^{2}$, and the event

\footnotetext{
${ }^{21}$ For empirical evidence showing that migration costs and amenity differences between destinations do matter, see Bryan and Morten (2015) and Morten and Oliveira (2014).
} 
that this difference is positive is as likely as the event that it is negative, given that $\psi_{i j}$ and $\psi_{i i}$ are independently and identically distributed. This means that high-skilled people's location preferences do not exhibit systematic home bias.

The assumptions giving rise to this feature are made mainly for technical convenience-however, this is without much loss of generality in so far as the main conclusion of the paper is concerned. Indeed, if the structure of the distribution of location preferences allowed for home bias, then it would become more difficult for any one country to attract foreign workers, given prospective immigrants' stronger attachment to their own homelands. In other words, the sensitivity of the mass of high-skilled immigrants to the utility option they are offered would be weaker. Hence, home bias would tend to keep the attraction effect from diverging and it would further support the asymptotic sustainability of at least some income redistribution, as discussed in Subsection 6.2. ${ }^{22}$ Introducing home bias would thus actually strengthen the main message of this paper, namely, that income redistribution can still be possible to some extent even with a very large number of governments competing with each other for skilled workers.

Home bias itself could be introduced, for example, by setting $\psi_{i i} \equiv 0$ for all $i \in N$ and requiring that the distribution of $\psi_{i j}$ have a positive mean for $j \in N$ and $j \neq i$, or by assuming that the distribution of the own-country location parameter is dominated in the first-order stochastic sense by the distribution of the location parameter corresponding to any other destination country.

\section{Concluding Remarks}

Hines (2006) asks the following question: "Will social welfare expenditures survive tax competition?" In this article, I have sought to demonstrate that they may, even with there being many countries in the world, and also that the precise answer crucially depends on the structure of the distribution of location preferences. In particular, if this distribution exhibits the statistical property of mildly increasing left tail, then countries' incentives to undercut each others' taxes levied on high-skilled workers become limited, and race to the bottom fails to occur: income redistribution is still possible, even in the presence of a large number of countries.

The distribution of location preferences, in turn, can be recovered from potentially observable characteristics using the estimation strategy outlined in Subsection 8.1, which informs the econometrician about whether the underlying distribution of location preferences exhibits a mildly increasing left tail or not-that is, whether brain drain leads to the asymptotic collapse of the welfare state. This analysis could be addressed in future empirical work.

Relaxing the key assumptions of the model-in particular, on governments' social objectives-also provides a fruitful avenue for further research. Nevertheless, the assumption of Rawlsian social-welfare objectives is a useful benchmark, because it has made possible to give positive answers as to how much income redistribution is in

\footnotetext{
${ }^{22}$ The presence of home bias, on the other hand, would not change the conclusion that the retention effect vanishes asymptotically. Intuitively, no matter how much a person is attached to her homeland, she will always find another country she likes more if the number of countries is very large.
} 
the presence of tax competition, conditional on the normative assumption that governments believe there should be as much redistribution as possible towards their core populations. Different assumptions about social-welfare objectives would yield different answers, which become more difficult to interpret, given that governments strive for a lesser degree of redistribution even in the closed-economy benchmark if they exhibit non-Rawlsian objectives. That is, considering alternative social objectives is tantamount to replying to the question posed by Hines (2006) by another question: "Do you want social welfare expenditures to survive tax competition?"

At any rate, the specification of governments' social-welfare objectives is an inherently normative issue and several meaningful specifications are possible. Morelli et al. (2012, p. 149), for example, "ignore the complication that the total measure of residents relevant to future tax policy decisions is affected by the current decisions" and assume that while governments take the effects of migration on the budget constraint into account, they still maximize social welfare using weights according to the original composition of society. Alternatively, one may assume, as Bierbrauer et al. (2013, p. 297) do, that "the individuals whom a government cares for are exactly those individuals whom it taxes." This assumption makes not only the aggregate resource constraint but also the welfare criterion endogenous to the redistribution scheme to be implemented. ${ }^{23}$

Unlike the leading tradition of Mirrleesian optimal-taxation models, I consider only two skill types. I do so because the main goal of this paper is not to analyze the specific details of the shape of the tax function, but to present a general characterization of the extent to which income redistribution can be maintained in the presence of many countries and in the limit as the number of countries grows without bound, and also to see how this characterization depends on the distribution of migration costs. ${ }^{24}$ Restricting attention to the two-type case has the additional benefit that formal equilibrium existence and uniqueness results can be rigorously established, unlike in many continuous-type Mirrleesian taxation models, in which monotonicity constraints and the possibility of bunching are prone to cause complications (which, in turn, are often assumed away).

Nevertheless, in a tentative semi-formal analysis not reported in this paper, I extend both the continuous-type framework by Lehmann et al. (2014) with a Rawlsian objective and two countries and the one by Diamond (1998) with a generic social-welfare function and a single country, to a finite number of ex-ante symmetric countries. Both of these models involve an individual utility function that gives rise to the absence of income effects on labor supply. Numerical simulations suggest that the conclusions are qualitatively similar to those presented in this paper. In particular, whether at least

\footnotetext{
${ }^{23}$ One can also consider the case of Machiavellian governments led by self-interested politicians (Acemoglu et al., 2008). An overview of plausible social-welfare criteria in taxation models with labor mobility and their implications is provided by Mansoorian and Myers (1997).

${ }^{24}$ In addition, Wilson (1992) warns that assessing the degree of income redistribution based on the magnitude of marginal tax rates according to the optimal tax schedule can be misleading, even when the presence of strong migration propensities limits the government's ability to redistribute income. This is because it may be the case that the optimal tax schedule consists of disbursing a generous uniform subsidy, which is taxed away in a regressive way in turn.
} 
some redistribution is asymptotically feasible depends crucially on the shape of the tail of the probability density function representing idiosyncratic location preferences. Since the marginal sensitivity of the high-skilled population $m_{n}$ is completely determined by the distribution of location preferences with no reference to the social objective governments pursue - see (11) — these tentative results, together with Proposition 5 , indicate that the pivotal role that the mildy-increasing-left-tail property plays in determining the asymptotic sustainability of income redistribution is robust for alternative normative goals other than the Rawlsian social-welfare objective.

While I do assume that low-skilled people are immobile, I conjecture that this is not a major limitation. Indeed, Hamilton et al. (2002) and Piaser (2007) argue that the equilibrium open-economy redistribution scheme is unaffected by whether low-skilled people are assumed to be able to move or not, as long as governments have Rawlsian social-welfare objectives. ${ }^{25}$

The assumption of symmetry across countries is a natural benchmark as long as the lessons from the analysis are taken to apply to a large number of relatively homogeneous countries. The main advantage of this assumption is conceptual: the focus on the asymptotic outcome presupposes the ex-ante symmetry of countries and the restriction of attention to symmetric equilibria. Indeed, it is not straightforward to interpret the mere concept of asymptotics with asymmetric countries. At any rate, the symmetry assumption helps expose a mechanism that prevents tax competition from giving rise to race to the bottom: if high-skilled people are not sufficiently inclined to relocate (as captured by the statistical property of mildly increasing left tail), then governments have weaker incentives to attract them at the expense of lower taxes and the contraction of the welfare state. ${ }^{26}$

The assumption that the individual utility function is separable in consumption and effort is made for analytical convenience. While the shapes of redistribution schemes are quite sensitive to the exact utility specification (Saez, 2001), my main goal, then again, has been to characterize the asymptotic behavior of the equilibrium redistribution scheme qualitatively as opposed to providing a quantitative analysis of the minute details of the optimal tax function.

Future research could focus on relaxing the exogenous restriction that countries are forbidden from regulating migration flows. Endogenous immigration policies, according to which governments can selectively encourage or restrict the international movement of persons of different skill types, would also be welcome. ${ }^{27}$

\footnotetext{
${ }^{25}$ Borjas (1999) and Lehmann et al. (2014) argue, however, that in a continuous-type model, the correlation between skills and migration costs ought to be left unrestricted a priori. On the other hand, empirical evidence suggests that high-skilled people have a greater propensity to migrate than low-skilled people, indeed. See Chiquiar and Hanson (2005), who find that immigrants from Mexico into the United States tend to be relatively more educated and able to command higher wages.

${ }^{26}$ For related results on optimal open-economy redistribution with two asymmetric countries, see Leite-Monteiro (1997) and Lipatov and Weichenrieder (2012).

${ }^{27}$ Even with making immigration policies a strategic decision variable, certain plausible institutional constraints can still be imposed. Primarily, no person ought to be forbidden from leaving her country. As Bhagwati (1984) argues, the effective impediment to free movement
} 
Finally, the problem of tax competition between governments shares certain conceptual features with Cournot oligopoly with heterogeneous consumer tastes and product differentiation. In this analogy, governments can be thought of as the oligopolists, high-skilled people as the potential buyers, the redistribution scheme as product characteristics, and location preferences as tastes. In this line of industrial-organization literature, de Palma et al. $(1985 ; 1987)$ show that even though no pure-strategy Nash equilibrium exists in the baseline version of the classical model of Hotelling (1929), ${ }^{28}$ existence can be restored if consumer choice involves some idiosyncratic random component interpreted as tastes. ${ }^{29}$ Mutatis mutandis, the ideas and techniques expressed in this paper may help refine the conclusions drawn from the analysis of related industrial-organization models, too. In particular, it would be interesting to see how the strength and structure of idiosyncratic consumer tastes limit the extent to which consumers gain from greater competition in the presence of a large number of oligopolists.

\section{References}

ABEL, G. J. AND N. SANDER (2014): "Quantifying Global International Migration Flows," Science, 343, 1520-1522.

Acemoglu, D., M. Golosov, AND A. Tsyvinski (2008): "Markets versus Governments," Journal of Monetary Economics, 55, 159-189.

Aliprantis, C. D. AND K. C. Border (2006): Infinite Dimensional Analysis: A Hitchhiker's Guide, Berlin: Springer-Verlag.

Bagnoli, M. And T. Bergstrom (2005): "Log-Concave Probability and Its Applications," Economic Theory, 26, 445-469.

of persons tends to be immigration policies of destination countries in practice. Alternatively, endogenous immigration policies can be substituted for by allowing international transfer payments-see Mansoorian and Myers (1993) and Wildasin (1994), who show that the optimal redistribution scheme may involve governments paying aids to potential immigrants in order to stave off the adverse effects of migration on social welfare. From a worldwide utilitarian point of view, Weyl (2014) argues that migration from low-income countries to high-income ones can mitigate global inequalities for want of international transfer payments, even if the recipient countries exhibit a great degree of local inequality or authoritarian and oppressive governance.

${ }^{28}$ Shaked (1982), however, shows that a Nash equilibrium exists in mixed strategies, in spite of discontinuities.

${ }^{29}$ Rochet and Stole (2002) present a model of oligopolistic non-linear pricing with differentiated products and stochastic participation, in which firms seek to maximize the surplus to be extracted from prospective customers. In this framework, two types of idiosyncratic uncertainty about consumer preferences are posited: vertical (interpreted as how much the consumer values product quality) and horizontal (interpreted as random outside options, determining participation and which firm the consumer will purchase the good from). In the current framework, skill types represent vertical uncertainty and location preferences stand for horizontal idiosyncrasies. 
BhaGWATI, J. N. (1984): "Incentives and Disincentives: International Migration," Weltwirtschaftliches Archiv, 120, 678-701.

Bhagwati, J. N. And K. Hamada (1982): "Tax Policy in the Presence of Emigration," Journal of Public Economics, 18, 291-317.

BhaGWATI, J. N. AND J. D. WILSON, eds. (1989): Income Taxation and International Mobility, Cambridge: The MIT Press.

Bierbrauer, F., C. Brett, AND J. A. Weymark (2013): "Strategic Nonlinear Income Tax Competition with Perfect Labor Mobility," Games and Economic Behavior, 82, 292-311.

Blackorby, C., W. Bossert, And D. Donaldson (2005): Population Issues in Social Choice Theory, Welfare Economics, and Ethics, New York: Cambridge University Press.

BORJAS, G. J. (1999): “The Economic Analysis of Immigration," in Handbook of Labor Economics, ed. by O. Ashenfelter and D. Card, Amsterdam: Elsevier, vol. 3A, 16971760.

Bryan, G. AND M. MORTEN (2015): “Economic Development and the Spatial Allocation of Labor: Evidence from Indonesia," Manuscript, London School of Economics and Stanford University.

Campbell, A. L. (2003): How Policies Make Citizens: Senior Political Activism and the American Welfare State, Princeton: Princeton University Press.

CAPlin, A. AND B. Nalebuff (1997): "Competition among Institutions," Journal of Economic Theory, 72, 306-342.

Castles, S., H. De HaAs, ANd M. J. Miller (2013): The Age of Migration: International Population Movements in the Modern World, New York: Guilford Press.

ChIQUiar, D. AND G. H. HANSON (2005): “International Migration, Self-Selection, and the Distribution of Wages: Evidence from Mexico and the United States," Journal of Political Economy, 113, 239-281.

de Palma, A., V. Ginsburgh, Y. Y. Papageorgiou, and J.-F. Thisse (1985): “The Principle of Minimum Differentiation Holds under Sufficient Heterogeneity," Econometrica, 53, 767-781.

De Palma, A., V. GinsburGh, AND J.-F. Thisse (1987): “On Existence of Location Equilibria in the 3-Firm Hotelling Problem," The Journal of Industrial Economics, 36, 245-252.

DiAmond, P. A. (1998): “Optimal Income Taxation: An Example with a U-Shaped Pattern of Optimal Marginal Tax Rates," The American Economic Review, 88, 83-95.

Folland, G. B. (1999): Real Analysis: Modern Techniques and Their Applications, New York: John Wiley \& Sons.

Gaughan, E. D. (1998): Introduction to Analysis, Providence: American Mathematical Society. 
Goldin, I., G. Cameron, and M. Balarajan (2011): Exceptional People: How Migration Shaped Our World and Will Define Our Future, Princeton: Princeton University Press.

Golosov, M., A. Tsyvinski, ANd I. Werning (2007): “New Dynamic Public Finance: A User's Guide," in NBER Macroeconomics Annual 2006, ed. by D. Acemoglu, K. Rogoff, and M. Woodford, Cambridge: The MIT Press, vol. 21, 317-363.

Gordon, R. H. AND J. B. Cullen (2012): “Income Redistribution in a Federal System of Governments," Journal of Public Economics, 96, 1100-1109.

Gordon, R. H. AND J. R. Hines, JR. (2002): “International Taxation," in Handbook of Public Economics, ed. by A. J. Auerbach and M. Feldstein, Amsterdam: Elsevier, vol. 4, 1935-1995.

Hamilton, J., J.-M. Lozachmeur, And P. Pestieau (2002): “Rawlsian Governments and the Race to the Bottom," Economics Bulletin, 8, 1-6.

Hamilton, J. And P. Pestieau (2005): “Optimal Income Taxation and the Ability Distribution: Implications for Migration Equilibria," International Tax and Public Finance, $12,29-45$.

HINES, JR., J. R. (2006): “Will Social Welfare Expenditures Survive Tax Competition?" Oxford Review of Economic Policy, 22, 330-348.

Hines, JR., J. R. AND L. H. Summers (2009): "How Globalization Affects Tax Design," in Tax Policy and the Economy, ed. by J. R. Brown and J. M. Poterba, Chicago: The University of Chicago Press, vol. 23, 123-158.

Hotelling, H. (1929): “Stability in Competition," The Economic Journal, 39, 41-57.

ITSKHOKI, O. (2008): "Optimal Redistribution in an Open Economy," Job-market paper, Harvard University.

Kleven, H. J., C. Landais, AND E. Saez (2013): “Taxation and International Migration of Superstars: Evidence from the European Football Market," The American Economic Review, 103, 1892-1924.

Kleven, H. J., C. Landais, E. SaeZ, And E. SChultz (2014): "Migration and Wage Effects of Taxing Top Earners: Evidence from the Foreigners' Tax Scheme in Denmark," The Quarterly Journal of Economics, 129, 333-378.

Kotlikoff, L. J. AND S. Burns (2005): The Coming Generational Storm: What You Need to Know about America's Economic Future, Cambridge: The MIT Press.

LehmanN, E., L. Simula, And A. Trannoy (2014): “Tax Me If You Can! Optimal Nonlinear Income Tax between Competing Governments," The Quarterly Journal of Economics, 129, 1995-2030.

Leite-Monteiro, M. (1997): "Redistributive Policy with Labour Mobility across Countries," Journal of Public Economics, 65, 229-244. 
Lipatov, V. AND A. Weichenrieder (2012): “Optimal Income Taxation with Tax Competition," Working Paper No. 12/07, Oxford University Centre for Business Taxation.

LYNCH, J. (2006): Age in the Welfare State: The Origins of Social Spending on Pensioners, Workers, and Children, New York: Cambridge University Press.

Mansoorian, A. AND G. M. Myers (1993): "Attachment to Home and Efficient Purchases of Population in a Fiscal Externality Economy," Journal of Public Economics, 52, 117-132.

(1997): “On the Consequences of Government Objectives for Economies with Mobile Populations," Journal of Public Economics, 63, 265-281.

Mendoza, E. G. AND L. L. Tesar (2005): “Why Hasn't Tax Competition Triggered a Race to the Bottom? Some Quantitative Lessons from the EU," Journal of Monetary Economics, 52, 163-204.

MirrleES, J. A. (1971): "An Exploration in the Theory of Optimum Income Taxation," The Review of Economic Studies, 38, 175-208.

319-341.

MOrelli, M., H. YANG, AND L. Ye (2012): “Competitive Nonlinear Taxation and Constitutional Choice," American Economic Journal: Microeconomics, 4, 142-175.

MORTEN, M. AND J. OliveiRA (2014): “Migration, Roads and Labor Market Integration: Evidence from a Planned Capital City," Manuscript, Stanford University and Clemson University.

PIASER, G. (2007): "Labor Mobility and Income Tax Competition," in International Taxation Handbook: Policy, Practice, Standards, and Regulations, ed. by C. Read and G. N. Gregoriou, Burlington: CIMA Publishing, 73-94.

Prékopa, A. (1973): “On Logarithmic Concave Measures and Functions," Acta Scientiarum Mathematicarum, 34, 335-343.

Rochet, J.-C. AND L. A. StOle (2002): “Nonlinear Pricing with Random Participation," The Review of Economic Studies, 69, 277-311.

SAEZ, E. (2001): "Using Elasticities to Derive Optimal Income Tax Rates," The Review of Economic Studies, 68, 205-229.

SHAKED, A. (1982): “Existence and Computation of Mixed Strategy Nash Equilibrium for 3-Firms Location Problem," The Journal of Industrial Economics, 31, 93-96.

Simula, L. AND A. TRannoy (2010): “Optimal Income Tax under the Threat of Migration by Top-Income Earners," Journal of Public Economics, 94, 163-173.

WeYL, E. G. (2014): “The Openness-Equality Trade-Off in Global Redistribution," Manuscript, The University of Chicago. 
WILDASIN, D. E. (1994): “Income Redistribution and Migration," Canadian Journal of Economics, 27, 637-656.

WILSON, J. D. (1980): “The Effect of Potential Emigration on the Optimal Linear Income Tax," Journal of Public Economics, 14, 339-353.

(1982): “Optimal Income Taxation and Migration: A World Welfare Point of View," Journal of Public Economics, 18, 381-397.

(1992): "Optimal Income Taxation and International Personal Mobility," The American Economic Review Papers and Proceedings, 82, 191-196.

\section{Appendix A}

Proof of Proposition 1 Define

$$
\mathcal{C} \equiv\left\{(c, d, e) \in \mathbb{R}_{+}^{3} \mid u(d)-v(e) \geq u(c) \text { and }(1-\alpha) c \leq \alpha(z e-d)\right\}
$$

to be the constraint set corresponding to the optimization problem (2). I will first show that there exists a convex compact set $\widetilde{\mathcal{C}} \subseteq \mathbb{R}_{+}^{3}$ such that $\mathcal{C} \subseteq \widetilde{\mathcal{C}}$. To see this, consider high-skilled people's optimal labor-supply choice $\bar{e}$ according to the laissez-faire allocation-see (1). Now, choose $\tilde{c}>0$ so large that $u(\tilde{c})>u(z \bar{e})-v(\bar{e})$, which is possible because $\lim _{c \rightarrow \infty} u(c)=\infty$ by Assumption 2 . Suppose that $(c, d, e) \in \mathcal{C}$. Then, since $c \geq 0, d \leq z e$. If $c$ were greater than $\tilde{c}$, then it would follow that

$$
u(d)-v(e) \leq u(z e)-v(e) \leq u(z \bar{e})-v(\bar{e})<u(\tilde{c})<u(c),
$$

which would violate incentive compatibility. Hence, $c \leq \tilde{c}$, showing that if $(c, d, e) \in \mathcal{C}$, then $c \in[0, \tilde{c}]$. Next, invoke the condition in Assumption 2 according to which

$$
\lim _{e \rightarrow \infty}\{u(z e)-v(e)\}=-\infty
$$

Choose $\tilde{e}>0$ so large that $u(z e)-v(e)<u(0)$ whenever $e \geq \tilde{e}$ and let $\tilde{d} \equiv z \tilde{e}$. Suppose that $(c, d, e) \in \mathcal{C}$. By virtue of feasibility, $d \leq z e$. If $e$ were greater than $\tilde{e}$, then it would follow that

$$
u(d)-v(e) \leq u(z e)-v(e)<u(0) \leq u(c)
$$

which would violate incentive compatibility. Hence, if $(c, d, e) \in \mathcal{C}$, then $e \in[0, \tilde{e}]$, which implies also that $d \leq z e \leq z \tilde{e}=\tilde{d}$. Thus, letting $\widetilde{\mathcal{C}} \equiv[0, \tilde{c}] \times[0, \tilde{d}] \times[0, \tilde{e}]$, it is clear that $\mathcal{C} \subseteq \widetilde{\mathcal{E}}$.

By continuity of the functions $u$ and $v$, it is obvious that $\mathcal{C}$ is closed and hence compact, being the subset of the compact set $\widetilde{\mathcal{C}}$. It is also non-empty, as $(0,0,0) \in \mathcal{C}$, and the objective function $(c, d, e) \mapsto c$ is continuous, so a solution to (2) exists by Weierstrass's extreme-value theorem. To see uniqueness, suppose that both $\left(c^{\prime}, d^{\prime}, e^{\prime}\right)$ and $\left(c^{\prime \prime}, d^{\prime \prime}, e^{\prime \prime}\right)$ solve (2). Clearly, $c^{\prime}=c^{\prime \prime} \equiv c$. Now let $\lambda \in(0,1)$ and $\left(c^{\lambda}, d^{\lambda}, e^{\lambda}\right) \equiv$ 
$\lambda\left(c^{\prime}, d^{\prime}, e^{\prime}\right)+(1-\lambda)\left(c^{\prime \prime}, d^{\prime \prime}, e^{\prime \prime}\right)$. It is clear that $\left(c^{\lambda}, d^{\lambda}, e^{\lambda}\right)$ satisfies budget balance, too, and strict concavity implies that

$$
u\left(d^{\lambda}\right)-v\left(e^{\lambda}\right)>\lambda\left[u\left(d^{\prime}\right)-v\left(e^{\prime}\right)\right]+(1-\lambda)\left[u\left(d^{\prime \prime}\right)-v\left(e^{\prime \prime}\right)\right] \geq \lambda u\left(c^{\prime}\right)+(1-\lambda) u\left(c^{\prime \prime}\right)=u(c)
$$

whenever $\left(c^{\prime}, d^{\prime}, e^{\prime}\right) \neq\left(c^{\prime \prime}, d^{\prime \prime}, e^{\prime \prime}\right)$, so that the incentive-compatibility constraint becomes slack. The assumption that $\left(c^{\prime}, d^{\prime}, e^{\prime}\right) \neq\left(c^{\prime \prime}, d^{\prime \prime}, e^{\prime \prime}\right)$ implies also that at least one of $d^{\prime}, d^{\prime \prime}, e^{\prime}$, and $e^{\prime \prime}$ is strictly positive, and hence at least one of $d^{\lambda}$ and $e^{\lambda}$ is strictly positive. Without loss of generality, assume that $d^{\lambda}>0$. One can then slightly decrease $d^{\lambda}$ and still have the incentive-compatibility constraint slack, while the budget-balance constraint has now become slack, too. Therefore, one can increase $c$ slightly as well and still have both constraints satisfied. This contradicts the assumption that $\left(c^{\prime}, d^{\prime}, e^{\prime}\right)$ and $\left(c^{\prime \prime}, d^{\prime \prime}, e^{\prime \prime}\right)$ solve (2), which shows that the solution-henceforth denoted as $\left(c_{1}, d_{1}, e_{1}\right)$ is unique.

To see that $c_{1}>0$, observe that the laissez-faire allocation is feasible for problem (2): $(0, z \bar{e}, \bar{e}) \in \mathcal{C}$. Indeed, since $\bar{e}$ is the unique solution to (1), it follows that

$$
u(z \bar{e})-v(\bar{e})>u(0)-v(0)=u(0),
$$

and the budget-balance constraint is trivially satisfied. Let $d>0$ be slightly less than $z \bar{e}$ - so slightly that the incentive-compatibility constraint $u(d)-v(\bar{e})>u(0)$ is still slack. Then, the budget constraint becomes slack as well and one can choose $c>0$ slightly greater than zero-so slightly that both constraints are still satisfied. It follows that $(c, d, \bar{e}) \in \mathcal{C}$, showing that the optimal solution ought to a fortiori involve positive consumption of the low-skilled. In turn, the budget constraint implies that $e_{1}>0$. In addition,

$$
u\left(d_{1}\right)=u\left(d_{1}\right)-v(0)>u\left(d_{1}\right)-v\left(e_{1}\right) \geq u\left(c_{1}\right)
$$

by incentive compatibility, so $d_{1}>c_{1}>0$.

Finally, the Kuhn - Tucker theorem ${ }^{30}$ implies that the necessary first-order conditions associated with the solution $\left(c_{1}, d_{1}, e_{1}\right)$ to the problem (2) read as follows:

$$
\begin{aligned}
1-\lambda_{1} u^{\prime}\left(c_{1}\right)-\mu_{1}(1-\alpha) & =0, \\
\lambda_{1} u^{\prime}\left(d_{1}\right)-\mu_{1} \alpha & =0, \\
-\lambda_{1} v^{\prime}\left(e_{1}\right)+\mu_{1} \alpha z & =0,
\end{aligned}
$$

where $\lambda_{1} \geq 0$ and $\mu_{1} \geq 0$ denote the multipliers on the incentive-compatibility constraint and the budget-balance constraint, respectively. Rearranging (28) and (29) yields

${ }^{30}$ Taking a look at the signs of the components of the constraint functions' gradients at $\left(c_{1}, d_{1}, e_{1}\right)$ :

$$
\left[\begin{array}{r|r}
u^{\prime}\left(c_{1}\right) & \oplus \\
-u^{\prime}\left(d_{1}\right) & \ominus \\
v^{\prime}\left(e_{1}\right) & \oplus
\end{array}\right] \quad \text { and } \quad\left[\begin{array}{r|r}
1-\alpha & \oplus \\
\alpha & \oplus \\
-\alpha z & \ominus
\end{array}\right]
$$

reveals that these gradients are linearly independent. The constraint qualification is thus satisfied, so that the first-order conditions derived from the Kuhn-Tucker theorem are a valid characterization of the optimal solution $\left(c_{1}, d_{1}, e_{1}\right)$, indeed. 
(3). Moreover, since $u^{\prime}\left(c_{1}\right)>0, u^{\prime}\left(d_{1}\right)>0$, and $v^{\prime}\left(e_{1}\right)>0$ (see n. 6), (27) implies that at least one of $\lambda_{1}$ and $\mu_{1}$ does not vanish. However, if one of them vanishes, then both must vanish by (28) or (29), so neither of them vanishes: $\lambda_{1}>0$ and $\mu_{1}>0$. Hence, both constraints must bind, yielding (4) and (5).

\section{Appendix B}

Proof of Lemma 1 Since $h>0$, the function $H$ is strictly increasing, from which it readily follows that $M(x \mid y)$ is a strictly increasing function of $x$ for any fixed $y \in \mathbb{R}$.

Next, I show that the integral on the right-hand side of (8) is well-defined. Since the integral $\int_{\psi \in \mathbb{R}} h(\psi) \mathrm{d} \psi=1$ is finite and $h>0, h^{\prime}$ cannot be non-negative throughout the line. That is, there must exist some $\psi_{0} \in \mathbb{R}$ such that $h^{\prime}\left(\psi_{0}\right)<0$. Given that $h$ is log-concave, the derivative of $\log \circ h$, which is $h^{\prime} / h$, must be non-increasing. It follows that $h^{\prime}(\psi)<0$ for all $\psi \geq \psi_{0}$. Hence, $h$ is monotonically decreasing on the interval $\left[\psi_{0}, \infty\right)$ and bounded below by 0 , so $\lim _{\psi \rightarrow \infty} h(\psi)$ must exist. The finiteness of the integral $\int_{\psi \in \mathbb{R}} h(\psi) \mathrm{d} \psi=1$ implies that this limit must be zero. Using a similar argument, $\lim _{\psi \rightarrow-\infty} h(\psi)=0$. Therefore, there exists some $K>0$ such that $h(\psi)<1$ whenever $|\psi|>K$. Moreover, $h$ is continuous, so it must be bounded on the compact interval $[-K, K]$. It follows that $h$ is bounded throughout the real line: there exists some $B>0$ such that $h(\psi) \leq B$ for all $\psi \in \mathbb{R}$. Now, consider the integral on the right-hand side of (8):

$$
\begin{aligned}
& \int_{-\infty}^{\infty} h(\psi) h(\psi-(x-y))[1-H(\psi-(x-y))]^{n-2} \mathrm{~d} \psi \\
\leq & \int_{-\infty}^{\infty} h(\psi) h(\psi-(x-y)) \mathrm{d} \psi \leq \int_{-\infty}^{\infty} h(\psi) B \mathrm{~d} \psi=B<\infty,
\end{aligned}
$$

so this integral is well-defined, indeed.

To show that this integral is actually equal to $\partial M(x \mid y) / \partial x$ and, in particular, this derivative exists, define, for a fixed $y \in \mathbb{R}$ and $\psi \in \mathbb{R}$, the following function:

$$
G(x \mid \psi, y) \equiv n[1-H(\psi-(x-y))]^{n-1} \quad \text { for all } x \in \mathbb{R}
$$

and its partial derivative

$$
g(x \mid \psi, y) \equiv \frac{\partial G(x \mid \psi, y)}{\partial x}=n(n-1) h(\psi-(x-y))[1-H(\psi-(x-y))]^{n-2} .
$$

For the remainder of the proof, fix $x \in \mathbb{R}$. Consider any sequence $\left(x_{k}\right)_{k \in \mathbb{N}}$ of real numbers such that $\lim _{k \rightarrow \infty} x_{k}=x$ and $x_{k} \neq x$ for any $k \in \mathbb{N}$. Choose such real numbers $a, b$ that $a<b$ and $x_{k}$ and $x$ are all contained in the interval $[a, b]$ for all $k \in \mathbb{N}$. Still having $y \in \mathbb{R}$ fixed, define the following function for each $k \in \mathbb{N}$ :

$$
\Delta_{k}(\psi \mid y) \equiv h(\psi) \frac{G\left(x_{k} \mid \psi, y\right)-G(x \mid \psi, y)}{x_{k}-x} \quad \text { for all } \psi \in \mathbb{R}
$$


Note that

$$
\lim _{k \rightarrow \infty} \Delta_{k}(\psi \mid y)=h(\psi) g(x \mid \psi, y) \quad \text { for all } \psi \in \mathbb{R} .
$$

Moreover, Lagrange's mean-value theorem implies that there exists, for each $k \in \mathbb{N}$ and $\psi \in \mathbb{R}$, some $\xi_{k}(\psi) \in \mathbb{R}$ that is between $x_{k}$ and $x$ (and hence contained in the interval $[a, b])$ such that

$$
\Delta_{k}(\psi \mid y)=h(\psi) g\left(\xi_{k}(\psi) \mid \psi, y\right) \leq h(\psi) \sup _{\xi \in[a, b]} g(\xi \mid \psi, y) \leq h(\psi)[n(n-1) B],
$$

where $B$ is the upper bound on $h$ established supra. The point is that the functions $\left(\Delta_{k}(\cdot \mid y)\right)_{k \in \mathbb{N}}$ are uniformly dominated by the function $\psi \mapsto n(n-1) B h(\psi)$, which is clearly integrable given that $h$ is. Hence, Lebesgue's dominated convergence theorem (see Theorem 2.24 in Folland, 1999, pp. 54-55; cf. also Theorem 2.27 ibid., p. 56) implies that

$$
\begin{aligned}
\int_{-\infty}^{\infty} h(\psi) g(x \mid \psi, y) \mathrm{d} \psi & =\int_{-\infty}^{\infty} \lim _{k \rightarrow \infty} \Delta_{k}(\psi \mid y) \mathrm{d} \psi=\lim _{k \rightarrow \infty} \int_{-\infty}^{\infty} \Delta_{k}(\psi \mid y) \mathrm{d} \psi \\
& =\lim _{k \rightarrow \infty} \frac{M\left(x_{k} \mid y\right)-M(x \mid y)}{x_{k}-x}
\end{aligned}
$$

This implies that the map $x \mapsto M(x \mid y)$ is differentiable with respect to $x$ for any given $y \in \mathbb{R}$ and its derivative is given by (8), indeed.

Proof of Lemma 2 Suppose that $\left(x_{k}, y_{k}\right) \rightarrow(x, y)$ as $k \rightarrow \infty$ in $\mathbb{R}^{2}$. Then, since

$$
\lim _{k \rightarrow \infty}\left\{h(\psi)\left[1-H\left(\psi-\left(x_{k}-y_{k}\right)\right)\right]^{n-1}\right\}=h(\psi)[1-H(\psi-(x-y))]^{n-1} \quad \text { for all } \psi \in \mathbb{R}
$$

and the sequence of functions $\left(\psi \mapsto h(\psi)\left[1-H\left(\psi-\left(x_{k}-y_{k}\right)\right)\right]^{n-1}\right)_{k \in \mathbb{N}}$ is uniformly dominated by the integrable function $\psi \mapsto h(\psi)$, one can invoke again Lebesgue's dominated convergence theorem:

$$
\begin{aligned}
M(x \mid y) & =n \int_{-\infty}^{\infty} \lim _{k \rightarrow \infty}\left\{h(\psi)\left[1-H\left(\psi-\left(x_{k}-y_{k}\right)\right)\right]^{n-1}\right\} \mathrm{d} \psi \\
& =n \lim _{k \rightarrow \infty} \int_{-\infty}^{\infty} h(\psi)\left[1-H\left(\psi-\left(x_{k}-y_{k}\right)\right)\right]^{n-1} \mathrm{~d} \psi=\lim _{k \rightarrow \infty} M\left(x_{k} \mid y_{k}\right) .
\end{aligned}
$$

The result follows.

Proof of Lemma 3 I will first show that the function $(\psi, x) \mapsto 1-H(\psi-(x-y))$ is log-concave. Fix $y \in \mathbb{R}$ and define the function

$$
G(t) \equiv 1-H(-t+y) \quad \text { for all } t \in \mathbb{R} ;
$$

the argument referring to $y$-which is treated as a fixed parameter throughout the proof-is omitted for simplicity. Since the function $(\psi, x) \mapsto x-\psi$ is clearly concave, the function $G$ is strictly increasing, and

$$
1-H(\psi-(x-y))=G(x-\psi),
$$


it is sufficient to show that $G$ is log-concave. ${ }^{31}$

Fix $t \in \mathbb{R}$ and choose $\varepsilon \in(0, G(t))$. Note that $\lim _{s \rightarrow-\infty} G(s)=0$. Therefore, there exists some $s \in \mathbb{R}$ such that $s<t$ and $G(s)<\varepsilon$. Now, Cauchy's mean-value theorem implies the existence of such $\xi \in(s, t)$ that

$$
\frac{G^{\prime}(t)-G^{\prime}(s)}{G(t)-G(s)}=\frac{G^{\prime \prime}(\xi)}{G^{\prime}(\xi)}
$$

or

$$
\frac{h(-t+y)-h(-s+y)}{H(-s+y)-H(-t+y)}=-\frac{h^{\prime}(-\xi+y)}{h(-\xi+y)}
$$

The log-concavity of $h$ implies that $h^{\prime} / h$ is non-increasing. Hence, since $t>\xi$, it follows that

$$
-\frac{h^{\prime}(-t+y)}{h(-t+y)} \leq-\frac{h^{\prime}(-\xi+y)}{h(-\xi+y)}=\frac{h(-t+y)-h(-s+y)}{H(-s+y)-H(-t+y)} .
$$

Given that $s<t, H(-s+y)-H(-t+y)>0$, so multiplying both sides by the positive quantity $h(-t+y)[H(-s+y)-H(-t+y)]$ yields:

$$
\begin{aligned}
& -h^{\prime}(-t+y)[H(-s+y)-H(-t+y)] \leq h(-t+y)^{2}-h(-s+y) h(-t+y) \\
& <h(-t+y)^{2}
\end{aligned}
$$

given that $h>0$. Now, using this inequality, it follows that

$$
\begin{aligned}
\frac{\mathrm{d}}{\mathrm{d} t}\left[\frac{G^{\prime}(t)}{G(t)}\right] & =\frac{G^{\prime \prime}(t) G(t)-G^{\prime}(t)^{2}}{G(t)^{2}}=\frac{-h^{\prime}(-t+y)[1-H(-t+y)]-h(-t+y)^{2}}{G(t)^{2}} \\
& <\frac{-h^{\prime}(-t+y)[1-H(-t+y)]+h^{\prime}(-t+y)[H(-s+y)-H(-t+y)]}{G(t)^{2}} \\
& =\frac{-h^{\prime}(-t+y)[1-H(-s+y)]}{G(t)^{2}}=\frac{-h^{\prime}(-t+y) G(s)}{G(t)^{2}} .
\end{aligned}
$$

If $h^{\prime}(-t+y)>0$, then, clearly, $\mathrm{d}\left[G^{\prime}(t) / G(t)\right] / \mathrm{d} t<0$. If, on the other hand, $h^{\prime}(-t+y) \leq$ 0 , then, given that $G(s)<\varepsilon$,

$$
\frac{\mathrm{d}}{\mathrm{d} t}\left[\frac{G^{\prime}(t)}{G(t)}\right]<\frac{-h^{\prime}(-t+y) G(s)}{G(t)^{2}} \leq \frac{-h^{\prime}(-t+y) \mathcal{\varepsilon}}{G(t)^{2}} .
$$

Since $\varepsilon$ can be made arbitrarily small, it follows that

$$
\frac{\mathrm{d}}{\mathrm{d} t}\left[\frac{G^{\prime}(t)}{G(t)}\right] \leq 0
$$

in this case, too. Therefore, $G^{\prime}(t) / G(t)$ is locally non-increasing at $t$ and this is true for all $t \in \mathbb{R}$, showing that $\log \circ G$ is concave, as required, and thus so is the function

$$
(\psi, x) \mapsto 1-H(\psi-(x-y)) .
$$

\footnotetext{
${ }^{31}$ This proof hinges on ideas presented by Bagnoli and Bergstrom (2005).
} 
Therefore, the function defined as

$$
F(x, \psi \mid y) \equiv h(\psi)[1-H(\psi-(x-y))]^{n-1} \quad \text { for all }(x, \psi) \in \mathbb{R}^{2}
$$

is log-concave as well, being the product of log-concave functions. Finally, apply Theorem 6 in Prékopa (1973, p. 342) to conclude that

$$
M(x \mid y) \equiv n \int_{\psi \in \mathbb{R}} F(x, \psi \mid y) \mathrm{d} \psi
$$

is $\log$-concave, too, for any $y \in \mathbb{R}$.

\section{Appendix C}

In this appendix, I prove that there exists a unique symmetric equilibrium. This requires a series of lemmata first.

\section{C.1 Constraint Correspondence}

Fix any country $i \in N$ and assume that all other countries offer high-skilled people the outside option $y \in \mathbb{R}$ in terms of utilities. Define

$$
\begin{aligned}
\mathcal{C}(y) \equiv\left\{(c, d, e) \in \mathbb{R}_{+}^{3} \mid\right. & u(d)-v(e) \geq u(c), \\
& (1-\alpha) c \leq \alpha M(u(d)-v(e) \mid y)(z e-d)\}
\end{aligned}
$$

to be the constraint set corresponding to the optimization problem (10) of country $i$. Clearly, given that $v(0)=0,(0,0,0) \in \mathcal{C}(y)$ (that is, "shutting down" the economy is always feasible), so the constraint set is never empty.

Lemma 5 There exists a convex compact set $\widetilde{\mathcal{C}} \subseteq \mathbb{R}_{+}^{3}$ such that $\mathcal{C}(y) \subseteq \widetilde{\mathcal{C}}$ for any $y \in \mathbb{R}$.

Proof Following the exact same arguments as in the proof of Proposition 1, it is straightforward to check that the convex compact set $\widetilde{\mathcal{C}}$ defined therein contains $\mathcal{C}(y)$ for any $y \in \mathbb{R}$.

Lemma 6 For any $y \in \mathbb{R}$, the constraint set $\mathcal{C}(y)$ is compact.

Proof By virtue of Lemma 5, it is sufficient to prove that $\mathcal{C}(y)$ is closed, which follows easily from the continuity of the functions $u, v$, and $M(\cdot \mid y)$.

In the light of Lemma 5 , one can conceive of $\mathcal{C}$ as a correspondence mapping from $\mathbb{R}$ into the non-empty compact subset $\widetilde{\mathcal{C}}$ of $\mathbb{R}_{+}^{3}$. The next two lemmata establish the continuity of this correspondence.

Lemma 7 The constraint correspondence $\mathcal{C}: \mathbb{R} \rightarrow \widetilde{\mathcal{C}}$ is upper hemicontinuous. 
Proof Suppose that $y_{k} \rightarrow y$ as $k \rightarrow \infty$ in $\mathbb{R}$ and assume that $\left(c_{k}, d_{k}, e_{k}\right) \in \mathcal{C}\left(y_{k}\right)$ for all $k \in \mathbb{N}$. Since the sequence $\left(c_{k}, d_{k}, e_{k}\right)_{k \in \mathbb{N}}$ is contained in the compact set $\widetilde{\mathcal{C}}$, there exists a subsequence $\left(c_{k_{\ell}}, d_{k_{\ell}}, e_{k_{\ell}}\right)_{\ell \in \mathbb{N}}$ converging to some $(c, d, e) \in \widetilde{\mathcal{C}}$. The goal is to show that $(c, d, e) \in \mathcal{C}(y)$.

Incentive compatibility $u\left(d_{k_{\ell}}\right)-v\left(e_{k_{\ell}}\right) \geq u\left(c_{k_{\ell}}\right)$ holds for every $\ell \in \mathbb{N}$ and it is preserved in the limit by continuity:

$$
u(d)-v(e) \geq u(c) .
$$

Moreover, the budget constraint

$$
(1-\alpha) c_{k_{\ell}} \leq \alpha M\left(u\left(d_{k_{\ell}}\right)-v\left(e_{k_{\ell}}\right) \mid y_{k_{\ell}}\right)\left(z e_{k_{\ell}}-d_{k_{\ell}}\right)
$$

is also preserved in the limit by continuity (see, in particular, Lemma 2):

$$
(1-\alpha) c \leq \alpha M(u(d)-v(e) \mid y)(z e-d) .
$$

It follows that $(c, d, e) \in \mathcal{C}(y)$.

Lemma 8 The constraint correspondence $\mathcal{C}: \mathbb{R} \rightarrow \widetilde{\mathcal{C}}$ is lower hemicontinuous.

Proof Suppose that $y_{k} \rightarrow y$ as $k \rightarrow \infty$ in $\mathbb{R}$ and assume that $(c, d, e) \in \mathcal{C}(y)$. Define, for each $k \in \mathbb{N}$,

$$
c_{k} \equiv \min \left\{\frac{\alpha M\left(u(d)-v(e) \mid y_{k}\right)(z e-d)}{1-\alpha}, c\right\} \geq 0 .
$$

It is easy to see that $\left(c_{k}, d, e\right) \in \mathcal{C}\left(y_{k}\right)$ for each $k \in \mathbb{N}$ and that $\left(c_{k}, d, e\right)_{k \in \mathbb{N}}$ converges to $(c, d, e)$.

\section{C.2 Best-Reply Correspondence}

Define, for each $y \in \mathbb{R}$,

$$
\mathcal{R}(y) \equiv \underset{(c, d, e) \in \mathcal{C}(y)}{\arg \max } c
$$

to be the set of solutions to the problem (10) given $y$. Given that $\mathcal{C}(y)$ is non-empty and compact and the objective is continuous, Weierstrass's extreme-value theorem implies that $\mathcal{R}(y)$ is not empty for any $y \in \mathbb{R}$.

The next lemma shows that no solution to (10) can involve a slack budget constraint or no consumption for the low-skilled.

Lemma 9 If $(c, d, e) \in \mathcal{R}(y)$, then $(1-\alpha) c=\alpha M(u(d)-v(e) \mid y)(z e-d)$ and $c>0$.

Proof If $(1-\alpha) c<\alpha M(u(d)-v(e) \mid y)(z e-d)$, then, by continuity, one could slightly increase $d$ to $d+\varepsilon$ (where $\varepsilon>0$ is sufficiently small) such that the budget constraint is still slack and the incentive-compatibility constraint $u(d+\varepsilon)-v(e)>u(c)$ becomes slack. In turn, one could slightly increase $c$ so that both constraints still remain slack, 
contradicting optimality. Therefore, the budget constraint can never be slack in optimum.

Now consider the laissez-faire allocation $(0, z \bar{e}, \bar{e})$, where $\bar{e}>0$ is the unique maximizer of the function $e \mapsto u(z e)-v(e)$; see (1). By the unique maximization property of $\bar{e}$, it follows that

$$
u(z \bar{e})-v(\bar{e})>u(0)-v(0)=u(0),
$$

so that the laissez-faire allocation is incentive compatible. Clearly, the budget constraint is satisfied, too. Therefore, $(0, z \bar{e}, \bar{e}) \in \mathcal{C}(y)$. Now let $d>0$ be slightly less than $z \bar{e}$-so slightly that the incentive-compatibility constraint $u(d)-v(\bar{e})>u(0)$ is still slack. Then,

$$
\alpha M(u(d)-v(\bar{e}) \mid y)(z \bar{e}-d)>0,
$$

given that $M(\cdot \mid y)>0$, so that the budget constraint becomes slack. Choose $c>0$ slightly greater than zero-so slightly that both the incentive-compatibility constraint and the budget constraint are still slack, which is possible by continuity. Therefore, $(c, d, \bar{e}) \in \mathcal{C}(y)$, showing that any optimal solution ought to a fortiori involve positive consumption of the low-skilled.

Lemma 10 The best-reply correspondence $\mathcal{R}: \mathbb{R} \rightarrow \widetilde{\mathcal{C}}$, defined in (30), is upper hemicontinuous.

Proof Since the constraint correspondence $\mathcal{C}: \mathbb{R} \rightarrow \widetilde{\mathcal{C}}$ is non-empty and compactvalued by Lemma 6 and continuous by Lemmata 7 and 8, the result follows from Berge's maximum theorem (see Theorem 17.31 in Aliprantis and Border, 2006, pp. 570571).

In order to further characterize the best-reply correspondence $\mathcal{R}$, I exploit the logconcavity of the function $M(\cdot \mid y)$ (see Lemma 3 ).

Lemma 11 For any $y \in \mathbb{R}$, the function $(d, e) \mapsto \alpha M(u(d)-v(e) \mid y)(z e-d)$ is strictly quasi-concave on the convex region $\mathcal{D} \equiv\left\{(d, e) \in \mathbb{R}_{+}^{2} \mid z e-d>0\right\}$.

Proof Define the function $F(\cdot \mid y): \mathcal{D} \rightarrow \mathbb{R}$ by

$$
F(d, e \mid y) \equiv \alpha M(u(d)-v(e) \mid y)(z e-d) \quad \text { for all }(d, e) \in \mathcal{D} .
$$

Suppose that $\left(d^{\prime}, e^{\prime}\right)$ and $\left(d^{\prime \prime}, e^{\prime \prime}\right)$ are not equal, are both in $\mathcal{D}$, and satisfy

$$
\begin{gathered}
F\left(d^{\prime}, e^{\prime} \mid y\right) \geq t, \\
F\left(d^{\prime \prime}, e^{\prime \prime} \mid y\right) \geq t
\end{gathered}
$$

for some positive number $t>0$. I must show that

$$
F\left(d^{\lambda}, e^{\lambda} \mid y\right)>t
$$

for any $\lambda \in(0,1)$, where $d^{\lambda} \equiv \lambda d^{\prime}+(1-\lambda) d^{\prime \prime}$ and $e^{\lambda} \equiv \lambda e^{\prime}+(1-\lambda) e^{\prime \prime} .^{32}$

\footnotetext{
${ }^{32}$ If $t \leq 0$, then (31) holds trivially.
} 
Note that

$$
\begin{aligned}
& \log F\left(d^{\lambda}, e^{\lambda} \mid y\right)=\log \alpha+\log \circ M\left(u\left(d^{\lambda}\right)-v\left(e^{\lambda}\right) \mid y\right)+\log \left(z e^{\lambda}-d^{\lambda}\right) \\
& >\operatorname{\$ og} \alpha+\log \circ M\left(\lambda\left[u\left(d^{\prime}\right)-v\left(e^{\prime}\right)\right]+(1-\lambda)\left[u\left(d^{\prime \prime}\right)-v\left(e^{\prime \prime}\right)\right] \mid y\right)+\log \left(z e^{\lambda}-d^{\lambda}\right) \\
& \stackrel{\ominus}{\geq} \log \alpha+\lambda \log \circ M\left(u\left(d^{\prime}\right)-v\left(e^{\prime}\right) \mid y\right)+(1-\lambda) \log \circ M\left(u\left(d^{\prime \prime}\right)-v\left(e^{\prime \prime}\right) \mid y\right)+\log \left(z e^{\lambda}-d^{\lambda}\right) \\
& \stackrel{\text { 中 }}{\geq} \log \alpha+\lambda \log \circ M\left(u\left(d^{\prime}\right)-v\left(e^{\prime}\right) \mid y\right)+(1-\lambda) \log \circ M\left(u\left(d^{\prime \prime}\right)-v\left(e^{\prime \prime}\right) \mid y\right) \\
& +\lambda \log \left(z e^{\prime}-d^{\prime}\right)+(1-\lambda) \log \left(z e^{\prime \prime}-d^{\prime \prime}\right) \\
& =\lambda\left[\log \alpha+\log \circ M\left(u\left(d^{\prime}\right)-v\left(e^{\prime}\right) \mid y\right)+\log \left(z e^{\prime}-d^{\prime}\right)\right] \\
& +(1-\lambda)\left[\log \alpha+\log \circ M\left(u\left(d^{\prime \prime}\right)-v\left(e^{\prime \prime}\right) \mid y\right)+\log \left(z e^{\prime \prime}-d^{\prime \prime}\right)\right] \\
& =\lambda \log F\left(d^{\prime}, e^{\prime} \mid y\right)+(1-\lambda) \log F\left(d^{\prime \prime}, e^{\prime \prime} \mid y\right) \geq \log t \text {, }
\end{aligned}
$$

where the inequality $\boldsymbol{\phi}$ follows from the fact that the function $(d, e) \mapsto u(d)-v(e)$ is strictly concave and $\log \circ M$ is strictly increasing; $\nabla$ follows from Lemma 3 ; and $\$$ from the concavity of the function $(d, e) \mapsto \log (z e-d)$ on the region $\mathcal{D}$. The desired result follows.

Lemma 12 For any $y \in \mathbb{R}, \mathcal{R}(y)$ is a singleton.

Proof As argued supra, $\mathcal{R}(y)$ is not empty. To see that it cannot contain more than one point, assume that $\left(c^{\prime}, d^{\prime}, e^{\prime}\right) \in \mathcal{R}(y)$ and $\left(c^{\prime \prime}, d^{\prime \prime}, e^{\prime \prime}\right) \in \mathcal{R}(y)$. Since both choices are optimal, it must be that $c \equiv c^{\prime}=c^{\prime \prime}$. By Lemma 9, $c>0$, implying that $z e^{\prime}-d^{\prime}>0$ and $z e^{\prime \prime}-d^{\prime \prime}>0$ Pick any $\lambda \in(0,1)$ and define $d^{\lambda} \equiv \lambda d^{\prime}+(1-\lambda) d^{\prime \prime}$ and $e^{\lambda} \equiv \lambda e^{\prime}+(1-$ $\lambda) e^{\prime \prime}$. If $\left(d^{\prime}, e^{\prime}\right) \neq\left(d^{\prime \prime}, e^{\prime \prime}\right)$, then Lemma 11 implies that

$$
(1-\alpha) c<\alpha M\left(u\left(d^{\lambda}\right)-v\left(e^{\lambda}\right) \mid y\right)\left(z e^{\lambda}-d^{\lambda}\right),
$$

and the strict concavity of the function $(d, e) \mapsto u(d)-v(e)$ implies that

$$
u\left(d^{\lambda}\right)-v\left(e^{\lambda}\right)>u(c) .
$$

Therefore, $\left(c, d^{\lambda}, e^{\lambda}\right) \in \mathcal{C}(y)$ and both the budget constraint and the incentive-compatibility constraint are slack at this intermediate point. One can then obtain a feasible allocation with a slightly higher level of low-skilled consumption, contradicting optimality. Hence, it must be the case that $\left(c^{\prime}, d^{\prime}, e^{\prime}\right)=\left(c^{\prime \prime}, d^{\prime \prime}, e^{\prime \prime}\right)$.

\section{C.3 Existence and Uniqueness of Symmetric Equilibrium}

Now I am ready to prove Proposition 2.

Proof of Proposition 2 Consider the convex compact set $\widetilde{\mathcal{C}}$ whose existence has been established in Lemma 5. Define a function $R: \widetilde{\mathcal{C}} \rightarrow \widetilde{\mathcal{C}}$ by declaring $R(c, d, e)$ to be equal to the unique element of $\mathcal{R}(u(d)-v(e))(c f$. Lemma 12) for any $(c, d, e) \in \widetilde{\mathcal{C}}$. Since $\mathcal{R}$ is upper hemicontinuous as a correspondence by Lemma 10, it is continuous as a function. It follows that $R$ is a continuous function, mapping from and to the nonempty, convex, compact set $\widetilde{\mathcal{C}}$. Then, Brouwer's fixed-point theorem implies that $R$ 
must have a fixed point $\left(c^{*}, d^{*}, e^{*}\right) \in \widetilde{\mathcal{C}}$. By the definition of $R,\left(c^{*}, d^{*}, e^{*}\right) \in \mathcal{C}\left(u\left(d^{*}\right)-\right.$ $\left.v\left(e^{*}\right)\right)$, which concludes the proof of the existence of a symmetric equilibrium.

As for uniqueness of the symmetric equilibrium, suppose that both $\left(c^{\prime}, d^{\prime}, e^{\prime}\right)$ and $\left(c^{\prime \prime}, d^{\prime \prime}, e^{\prime \prime}\right)$ are symmetric equilibria. In any symmetry equilibrium, all countries offer high-skilled people the same utility level $y$, so the mass of high-skilled people in any given country is

$$
M(y \mid y)=n \int_{-\infty}^{\infty} h(\psi)[1-H(\psi)]^{n-1} \mathrm{~d} \psi=n\left[-\frac{[1-H(\psi)]^{n}}{n}\right]_{-\infty}^{\infty}=1 .
$$

Therefore, since the budget constraint cannot be slack by Lemma 9, it follows that the two symmetric equilibria satisfy

$$
\begin{aligned}
(1-\alpha) c^{\prime} & =\alpha\left(z e^{\prime}-d^{\prime}\right), \\
(1-\alpha) c^{\prime \prime} & =\alpha\left(z e^{\prime \prime}-d^{\prime \prime}\right) .
\end{aligned}
$$

I consider three mutually exclusive and essentially exhaustive cases.

Case $1 \quad c^{\prime}=c^{\prime \prime}$. Let $y^{\prime} \equiv u\left(d^{\prime}\right)-v\left(e^{\prime}\right)$ and $y^{\prime \prime} \equiv u\left(d^{\prime \prime}\right)-v\left(e^{\prime \prime}\right)$ and suppose, without loss of generality, that $y^{\prime} \geq y^{\prime \prime}$. Observe that

$$
\alpha M\left(y^{\prime} \mid y^{\prime \prime}\right)\left(z e^{\prime}-d^{\prime}\right) \geq \alpha M\left(y^{\prime \prime} \mid y^{\prime \prime}\right)\left(z e^{\prime}-d^{\prime}\right)=\alpha\left(z e^{\prime}-d^{\prime}\right)=(1-\alpha) c^{\prime}=(1-\alpha) c^{\prime \prime} .
$$

Hence, in the symmetric equilibrium $\left(c^{\prime \prime}, d^{\prime \prime}, e^{\prime \prime}\right)$, it is budget-feasible for any given country to offer $\left(c^{\prime \prime}, d^{\prime}, e^{\prime}\right)=\left(c^{\prime}, d^{\prime}, e^{\prime}\right)$, and this allocation also satisfies incentive compatibility given that it constitutes a symmetric equilibrium. If $\left(d^{\prime}, e^{\prime}\right) \neq\left(d^{\prime \prime}, e^{\prime \prime}\right)$, then, given that $c^{\prime}=c^{\prime \prime}>0$ by Lemma 9 so that $z e^{\prime}-d^{\prime}$ and $z e^{\prime \prime}-d^{\prime \prime}$ are both positive, Lemma 11 and the strict concavity of the function $(d, e) \mapsto u(d)-v(e)$ imply that

$$
\begin{aligned}
u\left(d^{\lambda}\right)-v\left(e^{\lambda}\right) & >u\left(c^{\prime \prime}\right), \\
(1-\alpha) c^{\prime \prime} & <\alpha M\left(u\left(d^{\lambda}\right)-v\left(e^{\lambda}\right) \mid y^{\prime \prime}\right)\left(z e^{\lambda}-d^{\lambda}\right),
\end{aligned}
$$

where $d^{\lambda} \equiv \lambda d^{\prime}+(1-\lambda) d^{\prime \prime}, e^{\lambda} \equiv \lambda e^{\prime}+(1-\lambda) e^{\prime \prime}$, and $\lambda \in(0,1)$. Hence, for some small $\varepsilon>0,\left(c^{\prime \prime}+\varepsilon, d^{\lambda}, e^{\lambda}\right)$ is still feasible when other countries offer $\left(c^{\prime \prime}, d^{\prime \prime}, e^{\prime \prime}\right)$, contradicting the fact that the latter is a symmetric equilibrium. It follows that if $c^{\prime}=c^{\prime \prime}$, then $\left(d^{\prime}, e^{\prime}\right)=$ $\left(d^{\prime \prime}, e^{\prime \prime}\right)$ is necessarily true as well. In words, no pair of different symmetric equilibria can offer low-skilled people the same consumption.

Case $2 \quad c^{\prime}>c^{\prime \prime}$ and $y^{\prime} \geq y^{\prime \prime}$, where, again, $y^{\prime} \equiv u\left(d^{\prime}\right)-v\left(e^{\prime}\right)$ and $y^{\prime \prime} \equiv u\left(d^{\prime \prime}\right)-v\left(e^{\prime \prime}\right)$. Pick $\varepsilon>0$ so small that $c^{\prime}>c^{\prime \prime}+\varepsilon$. By incentive compatibility of the equilibrium allocation $\left(c^{\prime}, d^{\prime}, e^{\prime}\right)$, it follows that

$$
y^{\prime} \geq u\left(c^{\prime}\right)>u\left(c^{\prime \prime}+\varepsilon\right)
$$

Hence, offering $\left(c^{\prime \prime}+\varepsilon, d^{\prime}, e^{\prime}\right)$ is incentive-compatible. But the greatest level of consumption any country can offer low-skilled people in the symmetric equilibrium $\left(c^{\prime \prime}, d^{\prime \prime}, e^{\prime \prime}\right)$ is $c^{\prime \prime}$, so offering $\left(c^{\prime \prime}+\varepsilon, d^{\prime}, e^{\prime}\right)$ must not be budget-feasible when other countries offer $\left(c^{\prime \prime}, d^{\prime \prime}, e^{\prime \prime}\right)$ :

$$
(1-\alpha)\left(c^{\prime \prime}+\varepsilon\right)>\alpha M\left(y^{\prime} \mid y^{\prime \prime}\right)\left(z e^{\prime}-d^{\prime}\right)
$$


Since $y^{\prime} \geq y^{\prime \prime}$ and the function $M\left(\cdot \mid y^{\prime \prime}\right)$ is increasing, this further implies that

$$
(1-\alpha)\left(c^{\prime \prime}+\varepsilon\right)>\alpha M\left(y^{\prime} \mid y^{\prime \prime}\right)\left(z e^{\prime}-d^{\prime}\right) \geq \alpha M\left(y^{\prime \prime} \mid y^{\prime \prime}\right)\left(z e^{\prime}-d^{\prime}\right)=\alpha\left(z e^{\prime}-d^{\prime}\right)=(1-\alpha) c^{\prime},
$$

so $c^{\prime \prime}+\varepsilon>c^{\prime}$, which is a contradiction.

Case $3 c^{\prime}>c^{\prime \prime}$ and $y^{\prime \prime}>y^{\prime}$. In this case, incentive compatibility of the equilibrium allocation $\left(c^{\prime}, d^{\prime}, e^{\prime}\right)$ implies that

$$
y^{\prime \prime}>y^{\prime} \geq u\left(c^{\prime}\right)>u\left(c^{\prime \prime}\right) .
$$

For $y \in\left\{y^{\prime}, y^{\prime \prime}\right\}$, define the function

$$
B(d, e \mid y) \equiv \alpha M(u(d)-v(e) \mid y)(z e-d) \quad \text { for all }(d, e) \in \mathbb{R}_{+}^{2},
$$

giving the right-hand side of the budget constraint. The inequalities in (35) entail that the incentive-compatibility constraint is slack in the symmetric equilibrium $\left(c^{\prime \prime}, d^{\prime \prime}, e^{\prime \prime}\right)$. I claim that this implies that the function $(d, e) \mapsto B\left(d, e \mid y^{\prime \prime}\right)$ is locally maximized at $\left(d^{\prime \prime}, e^{\prime \prime}\right)$. Indeed, by the slackness of the incentive-compatibility constraint and continuity of high-skilled people's utility, there exists an open neighborhood $U_{\left(d^{\prime \prime}, e^{\prime \prime}\right)}$ contained in the interior of $\mathbb{R}_{+}^{2}$ around $\left(d^{\prime \prime}, e^{\prime \prime}\right)$ (given that both $d^{\prime \prime}$ and $e^{\prime \prime}$ are easily seen to be strictly positive) such that the incentive-compatibility constraint is still slack in this neighborhood:

$$
u(d)-v(e)>u\left(c^{\prime \prime}\right) \quad \text { for all }(d, e) \in U_{\left(d^{\prime \prime}, e^{\prime \prime}\right)} .
$$

If $(d, e) \mapsto B\left(d, e \mid y^{\prime \prime}\right)$ were not locally maximized at $\left(d^{\prime \prime}, e^{\prime \prime}\right)$, then there would exist some $(d, e) \in U_{\left(d^{\prime \prime}, e^{\prime \prime}\right)}$ such that $B\left(d, e \mid y^{\prime \prime}\right)>B\left(d^{\prime \prime}, e^{\prime \prime} \mid y^{\prime \prime}\right)$. Hence, the budget constraint and the incentive-compatibility constraint can be made jointly slack. One can then find some consumption level of the low-skilled strictly greater than $c^{\prime \prime}$ that is still feasible, contradicting optimality. Hence, $(d, e) \mapsto B\left(d, e \mid y^{\prime \prime}\right)$ is locally maximized at $\left(d^{\prime \prime}, e^{\prime \prime}\right)$, for which a necessary condition is that both its partial derivatives vanish. Keeping in mind that $M\left(y^{\prime \prime} \mid y^{\prime \prime}\right)=1$, these two conditions are given as

$$
\begin{aligned}
\alpha m\left(y^{\prime \prime} \mid y^{\prime \prime}\right)\left(z e^{\prime \prime}-d^{\prime \prime}\right) u^{\prime}\left(d^{\prime \prime}\right) & =\alpha, \\
\alpha m\left(y^{\prime \prime} \mid y^{\prime \prime}\right)\left(z e^{\prime \prime}-d^{\prime \prime}\right) v^{\prime}\left(e^{\prime \prime}\right) & =\alpha z,
\end{aligned}
$$

where $m$ is as given in (8).

Now consider the other equilibrium $\left(c^{\prime}, d^{\prime}, e^{\prime}\right)$. I argue that

$$
\begin{aligned}
& \frac{\partial B\left(d^{\prime}, e^{\prime} \mid y^{\prime}\right)}{\partial d} \leq 0, \\
& \frac{\partial B\left(d^{\prime}, e^{\prime} \mid y^{\prime}\right)}{\partial e} \geq 0 .
\end{aligned}
$$

If this were not the case, say, $\partial B\left(d^{\prime}, e^{\prime} \mid y^{\prime}\right) / \partial d>0$, then one could slightly increase $d$ and make the budget constraint slack. But then the incentive-compatibility constraint would also become slack and one could find a consumption level of the lowskilled strictly greater than $c^{\prime}$, contradicting optimality. A similar argument shows that 
$\partial B\left(d^{\prime}, e^{\prime} \mid y^{\prime}\right) / \partial e<0$ is impossible. ${ }^{33}$ The conditions (38)-(39) can be expressed as follows:

$$
\begin{aligned}
\alpha m\left(y^{\prime} \mid y^{\prime}\right)\left(z e^{\prime}-d^{\prime}\right) u^{\prime}\left(d^{\prime}\right) & \leq \alpha, \\
\alpha m\left(y^{\prime} \mid y^{\prime}\right)\left(z e^{\prime}-d^{\prime}\right) v^{\prime}\left(e^{\prime}\right) & \leq \alpha z .
\end{aligned}
$$

Note that $m\left(y^{\prime} \mid y^{\prime}\right)=m\left(y^{\prime \prime} \mid y^{\prime \prime}\right)>0$, which common quantity I will denote as $m_{0}$ for simplicity. Also, $c^{\prime}>c^{\prime \prime}$ and the budget constraints (33)-(34) imply that

$$
z e^{\prime}-d^{\prime}>z e^{\prime \prime}-d^{\prime \prime}
$$

Hence, combining (36)-(37) and (40)-(41), it follows that

$$
\alpha m_{0}\left(z e^{\prime}-d^{\prime}\right) u^{\prime}\left(d^{\prime}\right) \leq \alpha=\alpha m_{0}\left(z e^{\prime \prime}-d^{\prime \prime}\right) u^{\prime}\left(d^{\prime \prime}\right)<\alpha m_{0}\left(z e^{\prime}-d^{\prime}\right) u^{\prime}\left(d^{\prime \prime}\right) .
$$

Consequently, $u^{\prime}\left(d^{\prime}\right)<u^{\prime}\left(d^{\prime \prime}\right)$, implying that $d^{\prime}>d^{\prime \prime}$. Similarly,

$$
\alpha m_{0}\left(z e^{\prime}-d^{\prime}\right) v^{\prime}\left(e^{\prime}\right) \leq \alpha z=\alpha m_{0}\left(z e^{\prime \prime}-d^{\prime \prime}\right) v^{\prime}\left(e^{\prime \prime}\right) \leq \alpha m_{0}\left(z e^{\prime}-d^{\prime}\right) v^{\prime}\left(e^{\prime \prime}\right) .
$$

Therefore, $v^{\prime}\left(e^{\prime}\right) \leq v^{\prime}\left(e^{\prime \prime}\right)$, from which it follows that $e^{\prime} \leq e^{\prime \prime}$. Finally, observe that

$$
y^{\prime} \equiv u\left(d^{\prime}\right)-v\left(e^{\prime}\right)>u\left(d^{\prime \prime}\right)-v\left(e^{\prime \prime}\right) \equiv y^{\prime \prime},
$$

which contradicts the initial assumption $y^{\prime \prime}>y^{\prime}$ for this case.

The analysis of the cases in which is $c^{\prime}<c^{\prime \prime}$ is completely analogous. Considering all these exhaustive cases, the impossibility for two distinct equilibria to exist follows. The proof is now complete.

\section{Appendix D}

This appendix provides a proof of Proposition 3. I prove a series of lemmata first.

Lemma 13 If $(c, d, e) \in \mathbb{R}_{+}^{3}$ solves (3)-(5), that is,

$$
\begin{aligned}
\frac{v^{\prime}(e)}{u^{\prime}(d)} & =z \\
u(d)-v(e) & =u(c), \\
(1-\alpha) c & =\alpha(z e-d),
\end{aligned}
$$

then $(c, d, e)$ coincides with the closed-economy benchmark allocation: $(c, d, e)=\left(c_{1}, d_{1}, e_{1}\right)$.

Proof Suppose that $(c, d, e) \in \mathbb{R}_{+}^{3}$ satisfies the assumptions of the lemma. If it were the case that $e>e_{1}$, then

$$
z u^{\prime}(d)=v^{\prime}(e)>v^{\prime}\left(e_{1}\right)=z u^{\prime}\left(d_{1}\right),
$$

\footnotetext{
${ }^{33}$ The only caveat to keep in mind in carrying out this analogous argument is to make sure $e^{\prime}$ can be decreased slightly, which is not possible if $e^{\prime}=0$. However, Lemma 9 implies that $c^{\prime}>0$, so that $e^{\prime}>0$.
} 
so $d<d_{1}$. Then,

$$
u(c)=u(d)-v(e)<u\left(d_{1}\right)-v\left(e_{1}\right)=u\left(c_{1}\right),
$$

which implies that $c<c_{1}$. However,

$$
(1-\alpha) c=\alpha(z e-d)>\alpha\left(z e_{1}-d_{1}\right)=(1-\alpha) c_{1}>(1-\alpha) c,
$$

leading to a contradiction. A completely analogous argument reveals that $e<e_{1}$ is impossible. Hence, it must be the case that $e=e_{1}$. Therefore,

$$
z u^{\prime}(d)=v^{\prime}(e)=v^{\prime}\left(e_{1}\right)=z u^{\prime}\left(d_{1}\right),
$$

so $d=d_{1}$ and

$$
(1-\alpha) c=\alpha(z e-d)=\alpha\left(z e_{1}-d_{1}\right)=(1-\alpha) c_{1},
$$

from which it follows that $c=c_{1}$.

Lemma 14 If $(c, d, e) \in \mathbb{R}_{+}^{3}$ satisfies

$$
\begin{aligned}
\frac{v^{\prime}(e)}{u^{\prime}(d)} & =z \\
u(d)-v(e) & >u(c), \\
(1-\alpha) c & =\alpha(z e-d),
\end{aligned}
$$

then $c<c_{1}, d>d_{1}$, and $e<e_{1}$.

Proof Suppose that $(c, d, e) \in \mathbb{R}_{+}^{3}$ satisfies the assumptions of the lemma. If it were the case that $e \geq e_{1}$, then

$$
z u^{\prime}(d)=v^{\prime}(e) \geq v^{\prime}\left(e_{1}\right)=z u^{\prime}\left(d_{1}\right),
$$

so $d \leq d_{1}$. Then,

$$
u(c)<u(d)-v(e) \leq u\left(d_{1}\right)-v\left(e_{1}\right)=u\left(c_{1}\right),
$$

which implies that $c<c_{1}$. However,

$$
(1-\alpha) c=\alpha(z e-d) \geq \alpha\left(z e_{1}-d_{1}\right)=(1-\alpha) c_{1}>(1-\alpha) c_{1}
$$

leading to a contradiction. Hence, it must be the case that $e<e_{1}$. Therefore,

$$
z u^{\prime}(d)=v^{\prime}(e)<v^{\prime}\left(e_{1}\right)=z u^{\prime}\left(d_{1}\right),
$$

so $d>d_{1}$ and

$$
(1-\alpha) c=\alpha(z e-d)<\alpha\left(z e_{1}-d_{1}\right)=(1-\alpha) c_{1},
$$

from which it follows that $c<c_{1}$. 
By definition, the symmetric equilibrium is characterized by the following problem:

$$
\begin{aligned}
\left\{\left(c_{n}, d_{n}, e_{n}\right)\right\}= & \underset{(c, d, e) \in \mathbb{R}_{+}^{3}}{\arg \max c} \quad \text { such that } \\
& \begin{aligned}
u(d)-v(e) & \geq u(c), \\
& (1-\alpha) c \leq \alpha M\left(u(d)-v(e) \mid y_{n}\right)(z e-d),
\end{aligned}
\end{aligned}
$$

where $y_{n} \equiv u\left(d_{n}\right)-v\left(e_{n}\right)$. The gradients of the two constraint functions evaluated at the equilibrium solution $\left(c_{n}, d_{n}, e_{n}\right)$ are given by ${ }^{34}$

$$
\left[\begin{array}{r}
u^{\prime}\left(c_{n}\right) \\
-u^{\prime}\left(d_{n}\right) \\
v^{\prime}\left(e_{n}\right)
\end{array}\right] \text { and }\left[\begin{array}{c}
1-\alpha \\
\alpha\left[1-m_{n} u^{\prime}\left(d_{n}\right)\left(z e_{n}-d_{n}\right)\right] \\
-\alpha\left[z-m_{n} v^{\prime}\left(e_{n}\right)\left(z e_{n}-d_{n}\right)\right]
\end{array}\right],
$$

where $m_{n}$ is as given in (11). Say that the constraint qualification is violated whenever the gradients corresponding to the binding constraints are linearly dependent. ${ }^{35}$ The following lemma states that this occurrence is very special:

Lemma 15 If the constraint qualification is violated at $\left(c_{n}, d_{n}, e_{n}\right)$, then $\left(c_{n}, d_{n}, e_{n}\right)=$ $\left(c_{1}, d_{1}, e_{1}\right)$ and

$$
m_{n}=\frac{\alpha u^{\prime}\left(c_{1}\right)+(1-\alpha) u^{\prime}\left(d_{1}\right)}{(1-\alpha) c_{1} u^{\prime}\left(c_{1}\right) u^{\prime}\left(d_{1}\right)}
$$

Proof Suppose that constraint qualification is violated. Given that both gradients in (42) are clearly non-zero, this is possible only if both constraints bind:

$$
\begin{aligned}
u\left(d_{n}\right)-v\left(e_{n}\right) & =u\left(c_{n}\right), \\
(1-\alpha) c_{n} & =\alpha\left(z e_{n}-d_{n}\right),
\end{aligned}
$$

and one of the gradients is a constant multiple of the other. That is, there must exist a (positive) real number $q$ such that

$$
\begin{aligned}
(1-\alpha) & =q u^{\prime}\left(c_{n}\right), \\
\alpha\left[1-m_{n} u^{\prime}\left(d_{n}\right)\left(z e_{n}-d_{n}\right)\right] & =-q u^{\prime}\left(d_{n}\right), \\
-\alpha\left[z-m_{n} v^{\prime}\left(e_{n}\right)\left(z e_{n}-d_{n}\right)\right] & =q v^{\prime}\left(e_{n}\right),
\end{aligned}
$$

or, after some rearragement,

$$
\begin{aligned}
\alpha & =\left[\alpha m_{n}\left(z e_{n}-d_{n}\right)-\frac{1-\alpha}{u^{\prime}\left(c_{n}\right)}\right] u^{\prime}\left(d_{n}\right), \\
\alpha z & =\left[\alpha m_{n}\left(z e_{n}-d_{n}\right)-\frac{1-\alpha}{u^{\prime}\left(c_{n}\right)}\right] v^{\prime}\left(e_{n}\right) .
\end{aligned}
$$

\footnotetext{
${ }^{34}$ Remember that $M\left(y_{n} \mid y_{n}\right)=1$; see (32).

${ }^{35}$ That the constraint qualification not be violated is a sufficient condition for the applicability of the Kuhn - Tucker theorem in order to characterize the symmetric equilibrium in terms of first-order conditions.
} 
Hence, $v^{\prime}\left(e_{n}\right) / u^{\prime}\left(d_{n}\right)=z$, so that Lemma 13 together with the fact that both constraints bind implies that $\left(c_{n}, d_{n}, e_{n}\right)=\left(c_{1}, d_{1}, e_{1}\right)$. Finally, plugging (44) into (45) yields (43) after some rearrangement, completing the proof.

Now I am ready to prove Proposition 3.

Proof of Proposition 3 By Lemma 9, the budget constraint always binds in the symmetric equilibrium and $c_{n}>0$. The binding budget constraint then implies that $e_{n}>0$ and the incentive-compatibility constraint, in turn, requires that $d_{n}>0$.

Next, I show that the constraint qualification is never violated in the symmetric equilibrium. If it is, then Lemma 15 implies that $\left(c_{n}, d_{n}, e_{n}\right)=\left(c_{1}, d_{1}, e_{1}\right)$. However, observe that

$$
\begin{aligned}
& {\left[\frac{\partial}{\partial d}\left[\alpha M\left(u(d)-v(e) \mid u\left(d_{1}\right)-v\left(e_{1}\right)\right)(z e-d)\right]\right]_{(d, e)=\left(d_{1}, e_{1}\right)} } \\
= & \alpha\left[m_{n} u^{\prime}\left(d_{1}\right)\left(z e_{1}-d_{1}\right)-1\right]=\frac{(1-\alpha) u^{\prime}\left(d_{1}\right)}{u^{\prime}\left(c_{1}\right)}>0,
\end{aligned}
$$

using the budget constraint $(1-\alpha) c_{1}=\alpha\left(z e_{1}-d_{1}\right)$ and (43). That is, the derivative of the right-hand side of the budget constraint with respect to $d$ is strictly positive in equilibrium, so any one country's government could slightly increase $d$ from $d_{1}$ and make both constraints slack. The government could then slightly increase $c$ from $c_{1}$, contradicting that $\left(c_{n}, d_{n}, e_{n}\right)=\left(c_{1}, d_{1}, e_{1}\right)$ is a symmetric equilibrium.

Having established that the constraint qualification must never be violated in any symmetric equilibrium, the Kuhn - Tucker theorem can be invoked in order to characterize the symmetric equilibrium in terms of first-order conditions. These conditions read as follows:

$$
\begin{aligned}
1-\lambda_{n} u^{\prime}\left(c_{n}\right)-\mu_{n}(1-\alpha) & =0, \\
\lambda_{n} u^{\prime}\left(d_{n}\right)-\mu_{n} \alpha\left[1-m_{n} u^{\prime}\left(d_{n}\right)\left(z e_{n}-d_{n}\right)\right] & =0, \\
-\lambda_{n} v^{\prime}\left(e_{n}\right)+\mu_{n} \alpha\left[z-m_{n} v^{\prime}\left(e_{n}\right)\left(z e_{n}-d_{n}\right)\right] & =0,
\end{aligned}
$$

where $\lambda_{n} \geq 0$ and $\mu_{n} \geq 0$ denote the multipliers on the incentive-compatibility constraint and the budget-balance constraint, respectively. Some algebraic manipulations and the binding budget constraint $(1-\alpha) c_{n}=\alpha\left(z e_{n}-d_{n}\right)$ yield:

$$
\begin{aligned}
\lambda_{n} u^{\prime}\left(c_{n}\right)+\mu_{n}(1-\alpha) & =1, \\
{\left[\lambda_{n}+\mu_{n}(1-\alpha) m_{n} c_{n}\right] u^{\prime}\left(d_{n}\right) } & =\mu_{n} \alpha, \\
{\left[\lambda_{n}+\mu_{n}(1-\alpha) m_{n} c_{n}\right] v^{\prime}\left(e_{n}\right) } & =\mu_{n} \alpha z .
\end{aligned}
$$

Observe that (47) and (48) readily imply that

$$
\frac{v^{\prime}\left(e_{n}\right)}{u^{\prime}\left(d_{n}\right)}=z
$$

Case $1 m_{n} \leq \bar{m}$. Suppose, by way of contradiction, that the incentive-compatibility constraint is slack. Then, Lemma 14 implies that $c_{n}<c_{1}, d_{n}>d_{1}$, and $e_{n}<e_{1}$. Moreover, $\lambda_{n}=0$, so (47) implies that

$$
m_{n}=\frac{\alpha}{(1-\alpha) u^{\prime}\left(d_{n}\right) c_{n}}>\frac{\alpha}{(1-\alpha) u^{\prime}\left(d_{1}\right) c_{1}}=\bar{m},
$$


a contradiction. Hence, the incentive-compatibility constraint must be binding, so Lemma 13 implies that $\left(c_{n}, d_{n}, e_{n}\right)=\left(c_{1}, d_{1}, e_{1}\right)$.

Case $2 m_{n}>\bar{m}$. Suppose, by way of contradiction, that the incentive-compatibility constraint binds. Then, Lemma 13 implies that $\left(c_{n}, d_{n}, e_{n}\right)=\left(c_{1}, d_{1}, e_{1}\right)$. Moreover, rearranging (47) yields ${ }^{36}$

$$
\frac{\lambda_{n}}{\mu_{n}}=\frac{\alpha-(1-\alpha) u^{\prime}\left(d_{1}\right) c_{1} m_{n}}{u^{\prime}\left(d_{1}\right)}<\frac{\alpha-(1-\alpha) u^{\prime}\left(d_{1}\right) c_{1} \bar{m}}{u^{\prime}\left(d_{1}\right)}=0,
$$

which is impossible. Therefore, the incentive-compatibility constraint must be slack, and Lemma 14 implies that $c_{n}<c_{1}, d_{n}>d_{1}$, and $e_{n}<e_{1}$. Also, rearranging (46) and (47), together with $\lambda_{n}=0$, yields (14).

\section{Appendix E}

Proof of Lemma 4 Fix $n \in \mathbb{N}, n \geq 2$. Recall that

$$
\begin{aligned}
m_{n} & \equiv n(n-1) \int_{-\infty}^{\infty} h(\psi)^{2}[1-H(\psi)]^{n-2} \mathrm{~d} \psi \\
& =\lim _{K \rightarrow \infty}\left\{\int_{-K}^{K} n(n-1) h(\psi)^{2}[1-H(\psi)]^{n-2} \mathrm{~d} \psi\right\} .
\end{aligned}
$$

Note also that

$$
\frac{\mathrm{d}}{\mathrm{d} \psi}\left\{-n[1-H(\psi)]^{n-1}\right\}=n(n-1) h(\psi)[1-H(\psi)]^{n-2} .
$$

Hence, integration by parts yields

$$
\begin{aligned}
m_{n}=\lim _{K \rightarrow \infty}\left\{\int_{-K}^{K} h(\psi)\left(n(n-1) h(\psi)[1-H(\psi)]^{n-2}\right) \mathrm{d} \psi\right\} \\
=\lim _{K \rightarrow \infty}\left\{-n h(K)[1-H(K)]^{n-1}+n h(-K)[1-H(-K)]^{n-1}\right. \\
\left.\quad+\int_{-K}^{K} n h^{\prime}(\psi)[1-H(\psi)]^{n-1} \mathrm{~d} \psi\right\} \\
=n \int_{-\infty}^{\infty} h^{\prime}(\psi)[1-H(\psi)]^{n-1} \mathrm{~d} \psi,
\end{aligned}
$$

given that $\lim _{K \rightarrow \infty} h(K)=\lim _{K \rightarrow-\infty} h(K)=0$ (see the proof of Lemma 1).

Using a reasoning very similar to that in the proof of Lemma 3, one can show that the log-concavity of $h$ implies that $H$ is also log-concave. ${ }^{37}$ Since $H$ is log-concave and

${ }^{36}$ Dividing by $\mu_{n}$ makes sense, for it is easy to see from (46) and (47) that $\mu_{n}>0$.

${ }^{37} \mathrm{Cf}$. Theorem 1 in Bagnoli and Bergstrom (2005, pp. 446-447), which establishes this result for probability density functions of bounded support. 
twice continuously differentiable, it follows that

$$
\frac{\mathrm{d}^{2} \psi}{\mathrm{d} \psi^{2}}[\log \circ H(\psi)]=\frac{h^{\prime}(\psi) H(\psi)-h(\psi)^{2}}{H(\psi)^{2}} \leq 0 \quad \text { for all } \psi \in \mathbb{R}
$$

Using (51), (52), and (50), it follows, after some algebra, that

$$
\begin{aligned}
m_{n+1}-m_{n} & =\int_{-\infty}^{\infty} h^{\prime}(\psi)[1-H(\psi)]^{n-1} \mathrm{~d} \psi-(n+1) \int_{-\infty}^{\infty} h^{\prime}(\psi) H(\psi)[1-H(\psi)]^{n-1} \mathrm{~d} \psi \\
& \geq \int_{-\infty}^{\infty} h^{\prime}(\psi)[1-H(\psi)]^{n-1} \mathrm{~d} \psi-(n+1) \int_{-\infty}^{\infty} h(\psi)^{2}[1-H(\psi)]^{n-1} \mathrm{~d} \psi \\
& =\frac{m_{n}}{n}-\frac{m_{n+1}}{n} .
\end{aligned}
$$

This implies that

$$
\frac{n+1}{n}\left(m_{n+1}-m_{n}\right) \geq 0,
$$

so that $m_{n+1} \geq m_{n}$. The claim follows by induction.

Proof of Proposition 4 If $m_{n^{\prime \prime}} \leq m_{n^{\prime}} \leq \bar{m}$ or $m_{n^{\prime \prime}} \leq \bar{m}<m_{n^{\prime}}$, then the claim follows directly from Proposition 3, so suppose that $\bar{m}<\bar{m}_{n^{\prime \prime}} \leq m_{n^{\prime}}$. Proposition 3 implies that the two symmetric equilibria $\left(c_{n^{\prime}}, d_{n^{\prime}}, e_{n^{\prime}}\right)$ and $\left(c_{n^{\prime \prime}}, d_{n^{\prime \prime}}, e_{n^{\prime \prime}}\right)$ must satisfy the following equations:

$$
\begin{aligned}
\frac{v^{\prime}\left(e_{n^{\prime}}\right)}{u^{\prime}\left(d_{n^{\prime}}\right)} & =z, & \frac{v^{\prime}\left(e_{n^{\prime \prime}}\right)}{u^{\prime}\left(d_{n^{\prime \prime}}\right)} & =z, \\
m_{n^{\prime}} & =\frac{\alpha}{(1-\alpha) u^{\prime}\left(d_{n^{\prime}}\right) c_{n^{\prime}}}, & m_{n^{\prime \prime}} & =\frac{\alpha}{(1-\alpha) u^{\prime}\left(d_{n^{\prime \prime}}\right) c_{n^{\prime \prime}}}, \\
(1-\alpha) c_{n^{\prime}} & =\alpha\left(z e_{n^{\prime}}-d_{n^{\prime}}\right), & (1-\alpha) c_{n^{\prime \prime}} & =\alpha\left(z e_{n^{\prime \prime}}-d_{n^{\prime \prime}}\right) .
\end{aligned}
$$

For the sake of contradiction, suppose that $e_{n^{\prime}}>e_{n^{\prime \prime}}$. Then,

$$
z u^{\prime}\left(d_{n^{\prime}}\right)=v^{\prime}\left(e_{n^{\prime}}\right)>v^{\prime}\left(e_{n^{\prime \prime}}\right)=z u^{\prime}\left(d_{n^{\prime \prime}}\right),
$$

from which it follows that $d_{n^{\prime \prime}}>d_{n^{\prime}}$. Since $m_{n^{\prime}} \geq m_{n^{\prime \prime}}$ by Lemma 4 , this implies also that $c_{n^{\prime \prime}}>c_{n^{\prime}}$. But then, the budget constraint entails that

$$
(1-\alpha) c_{n^{\prime}}=\alpha\left(z e_{n^{\prime}}-d_{n^{\prime}}\right)>\alpha\left(z e_{n^{\prime \prime}}-d_{n^{\prime \prime}}\right)=(1-\alpha) c_{n^{\prime \prime}}>(1-\alpha) c_{n^{\prime}},
$$

which is a contradiction. Hence, it must be the case that $e_{n^{\prime}} \leq e_{n^{\prime \prime}}$. This, in turn, implies that

$$
z u^{\prime}\left(d_{n^{\prime}}\right)=v^{\prime}\left(e_{n^{\prime}}\right) \leq v^{\prime}\left(e_{n^{\prime \prime}}\right)=z u^{\prime}\left(d_{n^{\prime \prime}}\right),
$$

so $d_{n^{\prime}} \geq d_{n^{\prime \prime}}$. Finally,

$$
(1-\alpha) c_{n^{\prime}}=\alpha\left(z e_{n^{\prime}}-d_{n^{\prime}}\right) \leq \alpha\left(z e_{n^{\prime \prime}}-d_{n^{\prime \prime}}\right)=(1-\alpha) c_{n^{\prime \prime}},
$$


so that $c_{n^{\prime}} \leq c_{n^{\prime \prime}}$.

Proof of Proposition 5 Recall from the proof of Lemma 4 that

$$
m_{n}=n \int_{-\infty}^{\infty} h^{\prime}(\psi)[1-H(\psi)]^{n-1} \mathrm{~d} \psi ;
$$

see (51). First, suppose that $h$ has mildly increasing left tail and let

$$
B \equiv \lim _{\psi \rightarrow-\infty} \frac{h^{\prime}(\psi)}{h(\psi)}<\infty
$$

Since $\log \circ h$ is log-concave, the function $h^{\prime} / h$ is non-increasing, so that

$$
\frac{h^{\prime}(\psi)}{h(\psi)} \leq B \quad \text { for all } \psi \in \mathbb{R}
$$

Therefore,

$$
\begin{aligned}
m_{n} & =n \int_{-\infty}^{\infty} h^{\prime}(\psi)[1-H(\psi)]^{n-1} \mathrm{~d} \psi=\int_{-\infty}^{\infty} \frac{h^{\prime}(\psi)}{h(\psi)}\left(n h(\psi)[1-H(\psi)]^{n-1}\right) \mathrm{d} \psi \\
& \leq B \int_{-\infty}^{\infty} n h(\psi)[1-H(\psi)]^{n-1} \mathrm{~d} \psi=B\left[-[1-H(\psi)]^{n}\right]_{-\infty}^{\infty}=B .
\end{aligned}
$$

Since this is true for any $n$, it follows that $\lim _{n \rightarrow \infty} m_{n} \leq B<\infty$, completing the proof of necessity.

As for sufficiency, suppose that $h$ does not have mildly increasing left tail. Fix an arbitrary positive real number $K>0$. Then, since

$$
\lim _{\psi \rightarrow-\infty} \frac{h^{\prime}(\psi)}{h(\psi)}=\infty,
$$

it follows that there exists some $\psi_{K} \in \mathbb{R}$ such that

$$
\frac{h^{\prime}(\psi)}{h(\psi)} \geq K \quad \text { for all } \psi \in\left(-\infty, \psi_{K}\right] .
$$

Let $^{38}$

$$
\underline{\psi} \equiv \inf \left\{\psi \in \mathbb{R} \mid h^{\prime}(\psi) \leq 0\right\} .
$$

Since $h^{\prime} / h$ is non-increasing, $h^{\prime}$ is continuous, and $h>0$, it follows that $h^{\prime}(\psi)>0$ whenever $\psi<\underline{\psi}$ and $h^{\prime}(\psi) \leq 0$ whenever $\psi \geq \underline{\psi}$. It is clear also that $\psi_{K}<\underline{\psi}$. Since $[1-H(\psi)]^{n-1} \leq[1-H(\underline{\psi})]^{n-1}$ for any $\psi \geq \underline{\psi}$, it follows that

$$
\int_{\underline{\psi}}^{\infty} h^{\prime}(\psi)[1-H(\psi)]^{n-1} \mathrm{~d} \psi \geq[1-H(\underline{\psi})]^{n-1} \int_{\underline{\psi}}^{\infty} h^{\prime}(\psi) \mathrm{d} \psi
$$

${ }^{38} \mathrm{As}$ argued in the proof of Lemma $1, h^{\prime}$ cannot be non-negative throughout the line. Hence, the set

$$
\left\{\psi \in \mathbb{R} \mid h^{\prime}(\psi) \leq 0\right\}
$$

is not empty. 


$$
=[1-H(\underline{\psi})]^{n-1}\left[\lim _{\psi \rightarrow \infty} h(\psi)-h(\underline{\psi})\right]=-h(\underline{\psi})[1-H(\underline{\psi})]^{n-1} .
$$

Now, observe that

$$
\begin{aligned}
m_{n} & =n \int_{-\infty}^{\infty} h^{\prime}(\psi)[1-H(\psi)]^{n-1} \mathrm{~d} \psi=\int_{-\infty}^{\psi_{K}} \frac{h^{\prime}(\psi)}{h(\psi)}\left(n h(\psi)[1-H(\psi)]^{n-1}\right) \mathrm{d} \psi \\
& +n \underbrace{\int_{\psi_{K}}^{\underline{\psi}} h^{\prime}(\psi)[1-H(\psi)]^{n-1} \mathrm{~d} \psi+n}_{\geq 0} \underbrace{\int_{\underline{\psi}}^{\infty}}_{\geq-h(\underline{\psi})[1-H(\underline{\psi})]^{n-1}} \\
& \geq K \int_{-\infty}^{h^{\prime}} n h(\psi)[1-H(\psi)]^{n-1} \mathrm{~d} \psi-n h(\underline{\psi})[1-H(\underline{\psi})]^{n-1} \\
& =K\left[-[1-H(\psi)]^{n}\right]_{-\infty}^{\psi_{K}}-n h(\underline{\psi})[1-H(\underline{\psi} \underline{\psi})]^{n-1} \\
& =K\left\{1-\left[1-H\left(\psi_{K}\right)\right]^{n}\right\}-n h(\underline{\psi})[1-H(\underline{\psi})]^{n-1} .
\end{aligned}
$$

Note that $\psi_{K}$ (and $\underline{\psi}$ ) can have been chosen (and defined) independently of $n$. Since it is easy to see that

$$
\lim _{n \rightarrow \infty}\left[1-H\left(\psi_{K}\right)\right]^{n}=\lim _{n \rightarrow \infty}\left\{n[1-H(\underline{\psi})]^{n-1}\right\}=0,
$$

it follows that

$$
\lim _{n \rightarrow \infty} m_{n} \geq K
$$

As $K$ can be made arbitrarily large, it follows that $\lim _{n \rightarrow \infty} m_{n}=\infty$.

Proof of Proposition 6 The sequences $\left(c_{n}\right)_{n=2}^{\infty},\left(d_{n}\right)_{n=2}^{\infty},\left(e_{n}\right)_{n=2}^{\infty}$ are monotonic by Proposition 4 and they are included in the compact sets $[0, \tilde{c}],[0, \tilde{d}]$, and $[0, \tilde{e}]$, respectively, by Lemma 5 (see also the proof of Proposition 1), so they are convergent. If $h$ has mildly increasing left tail and $m_{\infty} \leq \bar{m}$, then the claim follows directly from Proposition 3, since $m_{n} \leq m_{\infty} \leq \bar{m}$ for all $n$ given that the sequence $\left(m_{n}\right)_{n=2}^{\infty}$ is non-decreasing by Lemma 4.

If $h$ has mildly increasing left tail and $m_{\infty}>\bar{m}$, then there exists some $N \in \mathbb{N}$ such that $m_{n}>\bar{m}$ and thus $\left(c_{n}, d_{n}, e_{n}\right)$ satisfies (13)-(15) for all $n>N$ by Proposition 3. The claim then follows by taking limits and exploiting the continuity of the functions involved in (13)-(15). In addition, using Propositions 3 and 4, the following is true for any $n>N$ :

$$
\begin{aligned}
& c_{\infty} \leq c_{n}<c_{1}, \\
& d_{\infty} \geq d_{n}>d_{1} \\
& e_{\infty} \leq e_{n}<e_{1} .
\end{aligned}
$$

It is clear also that

$$
c_{\infty}=\frac{\alpha}{(1-\alpha) u^{\prime}\left(d_{\infty}\right) m_{\infty}}>0
$$


The asymptotic version of the budget constraint then implies that $z e_{\infty}>d_{\infty}$. If it were true that $e_{\infty} \leq \bar{e}$, then

$$
z u^{\prime}\left(d_{\infty}\right)=v^{\prime}\left(e_{\infty}\right) \leq v^{\prime}(\bar{e})=z u^{\prime}(z \bar{e})
$$

so that $z \bar{e} \leq d_{\infty}<z e_{\infty}$, a contradiction. Hence, it must be the case that $e_{\infty}>\bar{e}$, which implies that

$$
z u^{\prime}\left(d_{\infty}\right)=v^{\prime}\left(e_{\infty}\right)>v^{\prime}(\bar{e})=z u^{\prime}(z \bar{e})
$$

Therefore, $d_{\infty}<z \bar{e}$.

Finally, if $h$ does not have mildly increasing left tail, then $m_{\infty}=\infty$ by Proposition 5. Eventually, $m_{n}>\bar{m}$ applies, so $\left(c_{n}, d_{n}, e_{n}\right)$ satisfies (13)-(15) for $n$ large enough. Therefore,

$$
c_{n}=\frac{\alpha}{(1-\alpha) u^{\prime}\left(d_{n}\right) m_{n}} \leq \frac{\alpha}{(1-\alpha) u^{\prime}(\tilde{d}) m_{n}} .
$$

Since $m_{n} \rightarrow \infty, c_{n} \rightarrow 0$. The asymptotic version of the budget constraint then implies that $z e_{\infty}=d_{\infty}$, and efficiency requires even in the limit that $v^{\prime}\left(e_{\infty}\right)=z u^{\prime}\left(d_{\infty}\right)=$ $z u^{\prime}\left(z e_{\infty}\right)$. However, since the function $e \mapsto u(z e)-v(e)$ is strictly concave, this is possible only if $e_{\infty}=\bar{e}$ and $d_{\infty}=z \bar{e}$.

Proof of Proposition 7 Fix any $\varepsilon>0$ and consider the measure space $\left([-\varepsilon, \varepsilon], \mathscr{B}_{\varepsilon}, \mu_{\varepsilon}\right)$, where $\mathscr{B}_{\varepsilon}$ is the Borel $\sigma$-algebra on the interval $[-\varepsilon, \varepsilon]$ and $\mu_{\varepsilon}$ is the Lebesgue measure restricted thereto. Note that this is a finite measure space with $\mu_{\varepsilon}([-\varepsilon, \varepsilon])=2 \varepsilon$. Since $h_{k}$ restricted to $[-\varepsilon, \varepsilon]$ is continuous for any $k \in \mathbb{N}$, it is both absolutely integrable and square-integrable. That is,

$$
h_{k} \mid[-\mathcal{E}, \varepsilon] \in L^{1}\left([-\mathcal{E}, \varepsilon], \mathscr{B}_{\varepsilon}, \mu_{\varepsilon}\right) \cap L^{2}\left([-\mathcal{E}, \varepsilon], \mathscr{B}_{\mathcal{E}}, \mu_{\varepsilon}\right) .
$$

Observe also that

$$
\lim _{k \rightarrow \infty}\left\{\int_{-\varepsilon}^{\mathcal{E}} h_{k}(\psi) \mathrm{d} \psi\right\}=\lim _{k \rightarrow \infty}\left\{H_{k}(\varepsilon)-H_{k}(-\varepsilon)\right\}=1
$$

by (23).

Now, Proposition 6.12 in Folland (1999, p. 186) implies that

$$
\begin{gathered}
\int_{-\varepsilon}^{\mathcal{\varepsilon}} h_{k}(\psi) \mathrm{d} \psi=\left\|h_{k}\left|[-\varepsilon, \varepsilon]\left\|_{1} \leq \mu_{\varepsilon}([-\varepsilon, \varepsilon])^{1-1 / 2} \times\right\| h_{k}\right|[-\varepsilon, \varepsilon]\right\|_{2} \\
=\sqrt{2 \varepsilon} \times\left\|h_{k} \mid[-\varepsilon, \varepsilon]\right\|_{2}=\sqrt{2 \varepsilon \int_{-\varepsilon}^{\varepsilon} h_{k}(\psi)^{2} \mathrm{~d} \psi}
\end{gathered}
$$

where $\|\cdot\|_{1}$ and $\|\cdot\|_{2}$ denote the usual $L^{1}$ - and $L^{2}$-norms, respectively, or

$$
\frac{1}{2 \varepsilon}\left(\int_{-\varepsilon}^{\varepsilon} h_{k}(\psi) \mathrm{d} \psi\right)^{2} \leq \int_{-\varepsilon}^{\varepsilon} h_{k}(\psi)^{2} \mathrm{~d} \psi \leq \int_{-\infty}^{\infty} h_{k}(\psi)^{2} \mathrm{~d} \psi .
$$


Therefore, using (53),

$$
\frac{1}{2 \varepsilon}=\liminf _{k \rightarrow \infty}\left\{\frac{1}{2 \varepsilon}\left(\int_{-\varepsilon}^{\varepsilon} h_{k}(\psi) \mathrm{d} \psi\right)^{2}\right\} \leq \liminf _{k \rightarrow \infty}\left\{\int_{-\infty}^{\infty} h_{k}(\psi)^{2} \mathrm{~d} \psi\right\} .
$$

Since $\mathcal{E}$ can be made arbitrarily small, it follows that

$$
\liminf _{k \rightarrow \infty}\left\{\int_{-\infty}^{\infty} h_{k}(\psi)^{2} \mathrm{~d} \psi\right\}=\lim _{k \rightarrow \infty}\left\{\int_{-\infty}^{\infty} h_{k}(\psi)^{2} \mathrm{~d} \psi\right\}=\infty
$$

Invoking (24), it follows that

$$
m_{2, k}=2 \int_{-\infty}^{\infty} h_{k}(\psi)^{2} \mathrm{~d} \psi \rightarrow \infty \quad \text { as } k \rightarrow \infty
$$

by (54). For a fixed $k \in \mathbb{N}$, Lemma 4 implies that $m_{n, k} \geq m_{2, k}$ for all $n \geq 2$, so that

$$
\lim _{k \rightarrow \infty} m_{n, k}=\infty \quad \text { for all } n \geq 2 \text {. }
$$

That $\left(c_{n, k}, d_{n, k}, e_{n, k}\right) \rightarrow(0, z \bar{e}, \bar{e})$ as $k \rightarrow \infty$ (with $n$ being fixed) follows along pretty much the same lines as in the proof of Proposition 6 . The only caveat is that the sequences $\left(c_{n, k}\right)_{k \in \mathbb{N}},\left(d_{n, k}\right)_{k \in \mathbb{N}}$, and $\left(e_{n, k}\right)_{k \in \mathbb{N}}$ are not necessarily monotonic, so their limits are not guaranteed to exist a priori. However, given that $\lim _{k \rightarrow \infty} m_{n, k}=\infty$, it is not difficult to check that any subsequence $\left(c_{n, k_{\ell}}, d_{n, k_{\ell}}, e_{n, k_{\ell}}\right)_{\ell \in \mathbb{N}}$-where $\left(k_{\ell}\right)_{\ell \in \mathbb{N}}$ is a strictly increasing sequence of natural numbers - that converges at all must converge to $(0, z \bar{e}, \bar{e})$. By an argument similar to that presented in the proof of Theorem 1.15 in Gaughan (1998, pp. 50-51), this latter condition is sufficient to guarantee that $\left(c_{n, k}, d_{n, k}, e_{n, k}\right)_{k \in \mathbb{N}}$ itself converges to $(0, z \bar{e}, \bar{e})$, given also that the sequence is contained in the compact set $\widetilde{\mathrm{e}}$ by Lemma 5.39

\footnotetext{
${ }^{39}$ Note that $\widetilde{\complement}$ depends neither on $n$ nor on $k$-see the proof of Proposition 1.
} 